\title{
¿ocean Heat Storage in Response to Changing Ocean Circulation Processes
}

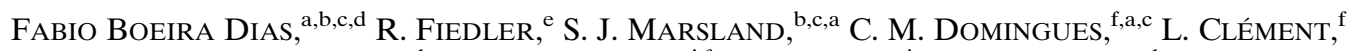 \\ S. R. Rintoul, ${ }^{\mathrm{e}, \mathrm{g}, \mathrm{h}}$ E. L. MCDOnAGH, ${ }^{\mathrm{i}, \mathrm{f}}$ M. M. MATA, ${ }^{\mathrm{j}}$ AND A. SAVITA ${ }^{\mathrm{a}, \mathrm{b}, \mathrm{c}}$ \\ ${ }^{\mathrm{a}}$ Institute for Marine and Antarctic Studies, University of Tasmania, Hobart, Tasmania, Australia; ${ }^{\mathrm{b}}$ CSIRO Oceans and \\ Atmosphere, Aspendale, Victoria, Australia; ${ }^{\mathrm{c}}$ ARC Centre of Excellence for Climate Extremes, University of Tasmania, Hobart, \\ Tasmania, Australia; ${ }^{\mathrm{d}}$ Institute for Atmospheric and Earth Science Research, University of Helsinki, Helsinki, Finland; ${ }^{\mathrm{e}}$ CSIRO \\ Oceans and Atmosphere, Hobart, Tasmania, Australia; ${ }^{\mathrm{f}}$ National Oceanographic Centre, Southampton, United Kingdom; ${ }^{\mathrm{g}}$ Centre \\ for Southern Hemisphere Oceans Research, Hobart, Tasmania, Australia; ${ }^{\mathrm{h}}$ Australian Antarctic Program Partnership, Hobart, \\ Tasmania, Australia; ${ }^{\mathrm{i}}$ NORCE, Norwegian Research Centre, Bjerknes Centre for Climate Research, Bergen, Norway; ${ }^{\mathrm{j}}$ Instituto de \\ Oceanografia, Universidade Federal do Rio Grande-FURG, Rio Grande, Brazil
}

(Manuscript received 31 December 2019, in final form 24 July 2020)

\begin{abstract}
Ocean heat storage due to local addition of heat ("added") and due to changes in heat transport ("redistributed") were quantified in ocean-only $2 \mathrm{xCO} 2$ simulations. While added heat storage dominates globally, redistribution makes important regional contributions, especially in the tropics. Heat redistribution is dominated by circulation changes, summarized by the super-residual transport, with only minor effects from changes in vertical mixing. While previous studies emphasized the contribution of redistribution feedback at high latitudes, this study shows that redistribution of heat also accounts for $65 \%$ of heat storage at low latitudes and $25 \%$ in the midlatitude $\left(35^{\circ}-50^{\circ} \mathrm{S}\right)$ Southern Ocean. Tropical warming results from the interplay between increased stratification and equatorward heat transport by the subtropical gyres, which redistributes heat from the subtropics to lower latitudes. The Atlantic pattern is remarkably distinct from other basins, resulting in larger basin-average heat storage. Added heat storage is evenly distributed throughout midlatitude Southern Ocean and dominates the total storage. However, redistribution stores heat north of the Antarctic Circumpolar Current in the Atlantic and Indian sectors, having an important contribution to the peak of heat storage at $45^{\circ} \mathrm{S}$. Southern Ocean redistribution results from intensified heat convergence in the subtropical front and reduced stratification in response to surface heat, freshwater, and momentum flux perturbations. These results highlight that the distribution of ocean heat storage reflects both passive uptake of heat and active redistribution of heat by changes in ocean circulation processes. The redistributed heat transport must therefore be better understood for accurate projection of changes in ocean heat uptake efficiency, ocean heat storage, and thermosteric sea level.
\end{abstract}

KEYWORDS: Ocean circulation; Ocean dynamics; Climate change; Climate sensitivity; Global transport modeling; Ocean models

\section{Introduction}

The ocean plays a central role in the climate system by absorbing $93 \%$ of the extra heat from anthropogenic emissions (Rhein et al. 2013) and mitigating surface warming (Stocker 2013). The observed multidecadal increase in global ocean heat content (OHC) (Domingues et al. 2008; Meyssignac et al. 2019), however, contributes to global mean sea level rise through thermal expansion (Cazenave et al. 2018). Both ocean warming and sea level rise are projected to continue increasing (Church et al. 2013; Oppenheimer et al. 2019).

In early conceptual studies, anthropogenic ocean heat storage (OHS) was considered to be solely a passive process by a time-mean circulation, along isopycnal ventilation pathways (Church et al. 1991; Jackett et al.2000). More recent studies highlight the importance of changing ocean circulation processes-the redistribution component-to global OHS and its spatial pattern (e.g., Banks and Gregory 2006; Xie and Vallis 2012; Garuba and Klinger

\footnotetext{
Denotes content that is immediately available upon publication as open access.
}

Corresponding author: Fabio Boeira Dias, fabio.boeiradias@ helsinki.fi
2016). Heat redistribution has been mostly attributed to changes in convection and isopycnal mixing at high latitudes (e.g., Gregory 2000). In an idealized Atlantic basin, Xie and Vallis (2012) demonstrated that heat redistribution increases the depth and efficiency of heat uptake, where slowdown of the Atlantic meridional overturning circulation (AMOC) causes a colder surface temperature, and results in a redistribution feedback that enhances the positive heat flux anomaly into the ocean. In a $\mathrm{CO}_{2}$ quadrupling experiment, the redistribution feedback explained $25 \%$ of the global OHS (Garuba and Klinger 2016), via a large contribution from the Atlantic due to AMOC slowdown (Xie and Vallis 2012) but also through changes in the wind-driven circulation (Garuba and Klinger 2018; H. Chen et al. 2019). Garuba and Klinger (2016) showed that changes in interbasin exchanges, via the Indonesian Throughflow and Southern Ocean, modulate heat uptake efficiency, and therefore global OHS and its spatial pattern.

We investigate the role of heat redistribution in OHS under idealized 2xCO2 experiments, following the Flux-Anomaly-

Publisher's Note: This article was revised on 2 October 2020 to fix errors in the affiliations for coauthors Marsland, Domingues, and Savita that were present when originally published. 


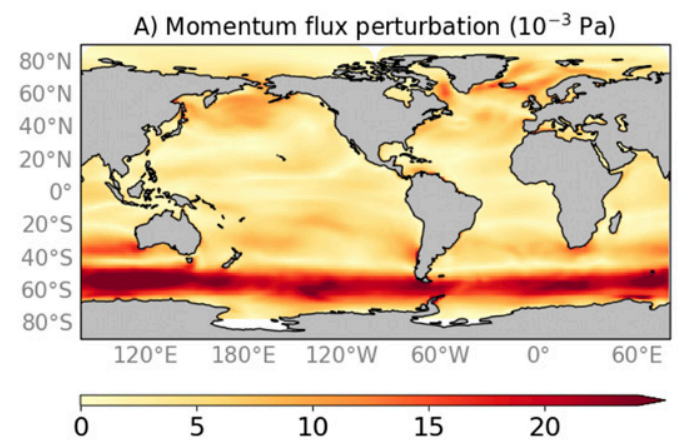

C) Freshwater flux perturbation $\left(10^{-6} \mathrm{~kg} \mathrm{~m}^{-2} \mathrm{~s}^{-1}\right)$

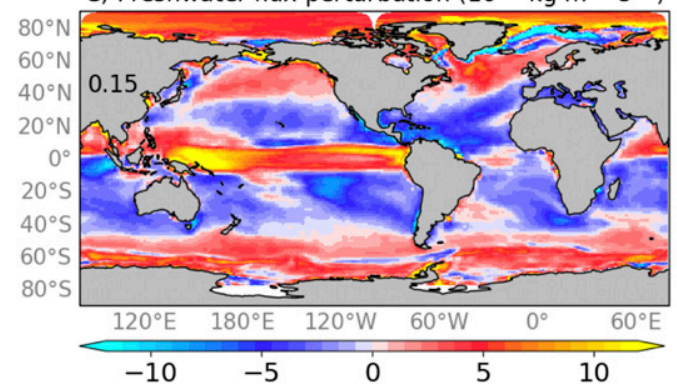

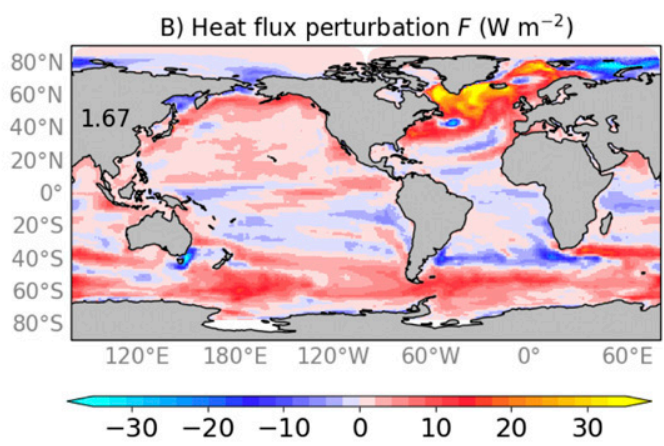

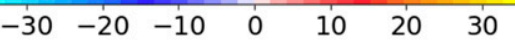

FIG. 1. Annual averaged FAFMIP perturbations of (a) momentum $\left(10^{-3} \mathrm{~Pa}\right)$, (b) heat $\left(\mathrm{W} \mathrm{m}^{-2}\right)$, and (c) freshwater fluxes $\left(10^{-6} \mathrm{~kg} \mathrm{~m}^{-2} \mathrm{~s}^{-1}\right)$. The global mean heat/freshwater input is show in the top-left corner for (b) and (c).

Forced Model Intercomparison Project (FAFMIP) protocol (Gregory et al. 2016). FAFMIP is part of phase 6 of the Coupled Model Intercomparison Project (CMIP6) (Eyring et al. 2016), and sensitivity experiments from participating model centers are forced by the same surface perturbation fluxes. Our model simulations highlight three regions where heat redistribution is important: the subpolar North Atlantic, the tropics, and the midlatitude Southern Ocean. Because the latter two regions have received much less attention than the AMOC weakening in the Atlantic (Banks and Gregory 2006; Xie and Vallis 2012; Winton et al. 2013; Marshall et al. 2015; Garuba and Klinger 2016; Gregory et al. 2016), we further explore their OHS mechanisms. In both the tropics and the midlatitude Southern Ocean, some studies have suggested that the passive component is dominant (Banks and Gregory 2006; Xie and Vallis 2012; Armour et al. 2016; Morrison et al. 2016). Our analyses, however, support the findings of Garuba et al. (2018) and H. Chen et al. (2019), demonstrating that heat redistribution due to changing ocean circulation processes plays a dominant role in tropical heat storage and influences the pattern of midlatitude Southern Ocean heat storage.

Details of the model setup, surface forcing, and perturbed experiments are found in section 2. Regional OHS and processbased analyses are presented in section 3 . The connections between redistributed OHS and changes in heat transport, ocean circulation, and stratification are explored in section 4 . Implications and caveats of these results are discussed in section 5 and conclusions are summarized in section 6 .

\section{Methods}

Our perturbed experiments were performed using an ocean general circulation model (OGCM), the ocean-sea ice model from the Australian Community Climate and Earth System Simulator (ACCESS-OM2; Kiss et al. 2020), with a nominal $1^{\circ}$ horizontal resolution. ACCESS-OM2 was initially spun up for 1000 years, under a climatological atmospheric state obtained from the JRA55-do repeated year (1984-85) forcing (Tsujino et al. 2018; Stewart et al. 2020), using bulk formulas to compute the turbulent heat fluxes, as in Dias et al. (2020). The 80-yr perturbed experiments were branched off from the spinup in year 1001. Except for the use of a prescribed salt flux from sea surface salinity (SSS) restoring, as explained below, in both control and perturbed runs, our ACCESSOM2 configuration is the same as in Dias et al.

Surface perturbation fluxes representative of a $2 \mathrm{xCO} 2$ scenario, as proposed for fully coupled climate (AOGCM) models in FAFMIP (Gregory et al. 2016), were added to the JRA55-do forcing to obtain a total of five perturbed runs: three singleforcing experiments (faf-heat, faf-water, and faf-stress) for heat, freshwater, and momentum (wind stress) perturbations respectively; an experiment combining all of them (faf-all); and a passive heat (faf-passiveheat) experiment. The latter uses the same perturbation as faf-heat but applied only to a passive tracer (added heat), whereas the ocean circulation is the same as in the control run. Perturbed results are presented as anomalies relative to the control run (at each time step) to remove model drift (Sen Gupta et al. 2013). FAFMIP surface flux anomalies were computed from a 13-member CMIP5 ensemble at years $61-80$ of a 1 pctCO2 scenario, where $2 \mathrm{xCO} 2$ was achieved around year 70 (Fig. 1). The main features of the flux perturbations are the strengthening and southward displacement of the westerly winds (faf-stress; Fig. 1a), strong positive heat flux anomalies in the Southern Ocean and in the North Atlantic subpolar region (faf-heat; Fig. 1b), and an 
TABLE 1. Summary of surface heat flux treatment.

\begin{tabular}{lll}
\hline \hline Quantity & \multicolumn{1}{c}{ Description } & Experiment \\
\hline$Q_{c}$ & Net surface heat flux & Control \\
$Q_{p}$ & Net surface heat flux & FAFMIP \\
$F$ & FAFMIP surface heat flux perturbation & faf-heat/faf-all \\
$\Delta Q=Q_{p}-Q_{c}$ & Ocean-driven surface feedback & FAFMIP \\
$Q_{+}=\Delta Q+F$ & Total surface heat flux perturbation & faf-heat/faf-all \\
\hline
\end{tabular}

intensification of the water cycle (precipitation minus evaporation) in faf-water (Fig. 1c).

As the surface freshwater (or salt) fluxes would be constrained by SSS restoring in the freshwater experiment, we changed ACCESS-OM2's configuration (60-day restoring time scale over the top layer with a nominal 10-m thickness) to a flux form. SSS restoring in OGCMs avoids unintended salinity drift (Danabasoglu et al. 2014). Although not the dominant term of the surface freshwater/salt budget in ACCESS-OM2 (Dias et al. 2020), restoring makes a significant contribution in regions of large SSS biases, such as in western boundary currents (WBCs) and along the Antarctic Circumpolar Current (ACC). For implementation of the flux form, the spinup was extended to year 1080, saving the surface salt fluxes from SSS restoring every $6 \mathrm{~h}$. A new control run was simulated for years 1001-80 with SSS restoring deactivated but prescribing the saved salt fluxes. In this way, we avoided spurious drifts (AMOC transport at $26.5^{\circ} \mathrm{N}$ decreases by only $2 \mathrm{~Sv}\left(1 \mathrm{~Sv} \equiv 10^{6} \mathrm{~m}^{3} \mathrm{~s}^{-1}\right)$ during the 80 -yr simulation) while maintaining a similar state to the spinup experiment.

\section{a. Added and redistributed heat}

Decomposition of ocean temperature into added and redistributed components has been done using different approaches (Banks and Gregory 2006; Xie and Vallis 2012; Winton et al. 2013; Marshall et al. 2015; Garuba et al. 2018). We follow the FAFMIP protocol, with two passive heat tracers (which do not affect density), added and redistributed, implemented in ACCESS-OM2 using the method B described in Bouttes and Gregory (2014) and Gregory et al. (2016). The added heat $T_{A}$ is initialized as zero and is only affected by the heat flux perturbation $F$ (Fig. 1b). The redistributed heat $T_{R}$ is initialized from the prognostic temperature $\theta_{p}$ and is not affected by $F$, but instead is only forced by the net surface heat flux $Q$. A schematic of the surface flux treatment is presented in Gregory et al. (2016, their Fig. 3).

An important aspect of method $\mathrm{B}$ is that $T_{R}$ provides the sea surface temperature (SST) for air-sea flux calculations; therefore, as the ocean circulation and SST evolve $\left(T_{R}\right.$ and $T_{A}$ are transported by the same perturbed processes $\Phi_{p}$ as $\theta_{p}$; see below), the (climatological) surface heat flux in the perturbed experiment $Q_{p}$ differs from the control $Q_{c}$. Hence, even though ACCESS-OM2 does not allow atmospheric feedbacks (constrained to the JRA55-do state), the turbulent fluxes are obtained via bulk formulas and an ocean-driven surface heat flux feedback occurs due to changes in the redistributed heat, referred to as a redistribution feedback (Garuba and Klinger 2016). In this case, $T_{R}$ is not purely redistribution, having a nonzero globally integrated anomaly because it includes the redistribution feedback.

The FAFMIP heat flux perturbation $F$ also includes part of the redistribution feedback from CMIP5 models, the source of the anomalous fluxes. This occurs because the multimodel perturbed fluxes were obtained as an anomaly from the mean state where the ocean redistribution (and the feedback) have changed systematically (e.g., at year 70, the AMOC slowdown is substantial). This effect is separated from the redistribution feedback resulting from $T_{R}$ changes in our individual model $\Delta Q$ (presented in Figs. 3c-f). So, it is correct to assume that the redistribution feedback has a component in $T_{A}$ (originating from CMIP5 models) and a component in $T_{R}$ due to changes in ocean processes in ACCESS-OM2.

The treatment for the surface fluxes (Table 1) and tracers (Table 2) are detailed below. Considering the mean surface heat flux anomaly between control $Q_{c}$ and perturbed $Q_{p}$ experiments (Gregory et al. 2016), the total surface heat flux perturbation $Q_{+}$in the faf-heat and faf-all experiments is given by

$$
Q_{+}=\left\langle Q_{p}\right\rangle+F-\left\langle Q_{c}\right\rangle=\langle\Delta Q\rangle+F,
$$

where the angle brackets $(\langle\rangle)$ indicate a time mean and $\Delta Q=$ $Q_{p}-Q_{c}$. Note that $\Delta Q$ will differ among OCGMs and AOGCMs due to active atmospheric changes in the latter [cf. Fig. 3f herein and Fig. 2d in Gregory et al. (2016)]. Using FAFMIP experiments from both AOCGMs and OGCMs, Todd et al. (2020) reported that atmospheric feedback is important in the North Atlantic, where cooling from $T_{R}$ at high latitudes enhances the prescribed surface heat flux perturbation and causes $10 \%$ additional AMOC weakening, while being negligible in the Southern Ocean. The surface heat fluxes in faf-stress and faf-water are only affected by the redistribution feedback $\Delta Q$.

The prognostic (conservative) temperature in our perturbed experiments $\theta_{p}$ is affected by both $Q_{p}$ and $F$, as defined by

$$
\frac{\partial \theta_{p}}{\partial t}=Q_{p}+F+\Phi_{p}\left(\theta_{p}\right)
$$

where $\Phi_{p}$ represents processes of heat transport in the perturbed state, including circulation, diffusion, eddies, vertical mixing, and so on [see Eq. (5)]. The prognostic temperature affects the ocean density and consequently changes the ocean circulation and ocean heat transport. As the redistributed heat $\left(T_{R}\right)$ is initiated from $\theta_{c}$ at year 1001 , we can define $T_{R}=\theta_{c}+$ $\Delta T_{R}$. Here, $T_{R}$ is not affected by the heat flux perturbation $F$ 
TABLE 2. Summary of heat tracers treatment.

\begin{tabular}{llll}
\hline \hline Tracer & \multicolumn{1}{c}{ Tracer equation } & \multicolumn{1}{c}{ Description } & Experiment \\
\hline$\theta_{c}$ & $\frac{\partial \theta_{c}}{\partial t}=Q_{c}+\Phi_{c}\left(\theta_{c}\right)$ & Conservative temperature & Control \\
$\theta_{p}$ & $\frac{\partial \theta_{p}}{\partial t}=Q_{p}+F+\Phi_{p}\left(\theta_{p}\right)$ & Conservative temperature & faf-heat/faf-all \\
$T_{R}$ & $\frac{\partial T_{R}}{\partial t}=Q_{p}+\Phi_{p}\left(T_{R}\right)$ & Redistributed heat & faf-heat/faf-all \\
$T_{A}$ & $\frac{\partial T_{A}}{\partial t}=F+\Phi_{p}\left(T_{A}\right)$ & Added heat & faf-heat/faf-all \\
$T_{A}$ & $\frac{\partial T_{A}}{\partial t}=F+\Phi_{c}\left(T_{A}\right)$ & Added heat & faf-passiveheat \\
\hline
\end{tabular}

and only affects the ocean density indirectly, via the oceandriven surface feedback, so the tracer equation is defined by

$$
\frac{\partial T_{R}}{\partial t}=Q_{p}+\Phi_{p}\left(T_{R}\right)
$$

The added heat tracer $T_{A}$ reveals where the extra heat from the heat flux perturbation $F$ is stored in the ocean. This tracer is initialized as zero and evolves with the same convergence fluxes as $\theta_{p}$, as defined by

$$
\frac{\partial T_{A}}{\partial t}=F+\Phi_{p}\left(T_{A}\right)
$$

The concept of passive warming represents the additional heat transported by the time-mean ocean circulation via the ventilation pathways of water mass formation (Church et al. 1991). The term $T_{A}$ accounts for the perturbed heat convergences $\Phi_{p}$ and therefore can differ from a passive tracer transported by the climatological (nonperturbed) state (Gregory et al. 2016). Results from faf-passiveheat (not shown), where $T_{A}$ is transported by the control heat convergence fluxes $\Phi_{c}$, show that the added heat is considerably stronger in the North Atlantic than in faf-heat or faf-all due to AMOC slowdown, but similar in other regions.

\section{b. Ocean heat budget}

To investigate further the relationship of OHS with physical processes of ocean heat transport (OHT), we included diagnostics for resolved and sub-gridscale processes contributing to OHT for all tracers $\left(\theta, T_{R}\right.$, and $\left.T_{A}\right)$. The heat fluxes $\Phi$ arise from the resolved advection (ADV) and several other parameterized terms. Given ACCESS-OM2's coarse resolution, the advection only represents the large-scale circulation, and processes such as eddy advection and isoneutral diffusion are parameterized through eddy-induced transport (EIT):

$$
\begin{aligned}
\Phi= & \mathrm{ADV}+\mathrm{DIA}+\mathrm{KPP}+\mathrm{SWP}+\mathrm{EIT} \\
& +\mathrm{SUB}+\mathrm{CON}+\mathrm{PME}+\mathrm{RIV}+\mathrm{FRZ} .
\end{aligned}
$$

While the diagnostics are similar to those detailed in Dias et al. (2020), here we treat the surface heat fluxes separately from the OHT processes, so $\Phi$ differs from $\mathbf{F}$ in Dias et al. Except for ADV, all the other processes in Eq. (5) are parameterized: DIA is the dianeutral diffusion, including background diffusivities and diffusivities enhanced by parameterizations (such as the local component of $K$-profile parameterization and the tidal mixing scheme); KPP is specifically the nonlocal component of $K$-profile parameterization (Large et al. 1994); SWP is the shortwave penetration through the water column; EIT includes both eddy advection (Gent et al. 1995) and isoneutral diffusion (Redi 1982; Griffies et al. 1998) parameterizations; SUB is the restratification effect from submesoscale eddies (Fox-Kemper et al. 2011); CON is the convective instabilities (Klinger et al. 1996) but also includes contributions from the downslope mixing and sigma diffusion (Snow et al. 2015) schemes that helps to transport dense water downward along lateral boundaries; PME is the heat flux from precipitation minus evaporation mass flux; RIV is the heat flux associated with river runoff; and FRZ is the heat flux associated with frazil ice formation.

\section{c. Super-residual framework}

Past studies of global vertical heat transport under a steady state indicated a balance between downward heat transport due to large-scale advection (ADV) and upward heat transport due to eddy-induced processes (EIT) (Gregory 2000; Gnanadesikan et al. 2005; Wolfe et al. 2008; Hieronymus and Nycander 2013; Exarchou et al. 2015; Griffies et al. 2015), where both advective and diffusive components of the EIT have similar effects (Kuhlbrodt et al. 2015; Dias et al. 2020). As definitions of advective and diffusive processes vary among models and generally depend on the horizontal grid scale that models can resolve, a consistent framework is required for model intercomparisons, such as the "super-residual" transport (SRT) - the superposition of ADV and EIT-first proposed by Kuhlbrodt et al. (2015). For example, for comparing the range of "eddy-permitting" models, which sometimes parameterize eddy (isoneutral) diffusion (Megann et al. 2014; Kuhlbrodt et al. 2015) and sometimes rely on it being resolved by the advection scheme (Wolfe et al. 2008; Morrison et al. 2013; Griffies et al. 2015).

Dias et al. (2020) investigated the SRT role in the quasisteady state of the ACCESS-OM2. In the global integral, they found that while ADV and EIT transport heat downward and upward respectively, the SRT revealed two depth-regimes with opposite contributions (their Fig. 13). In the regime of deep 


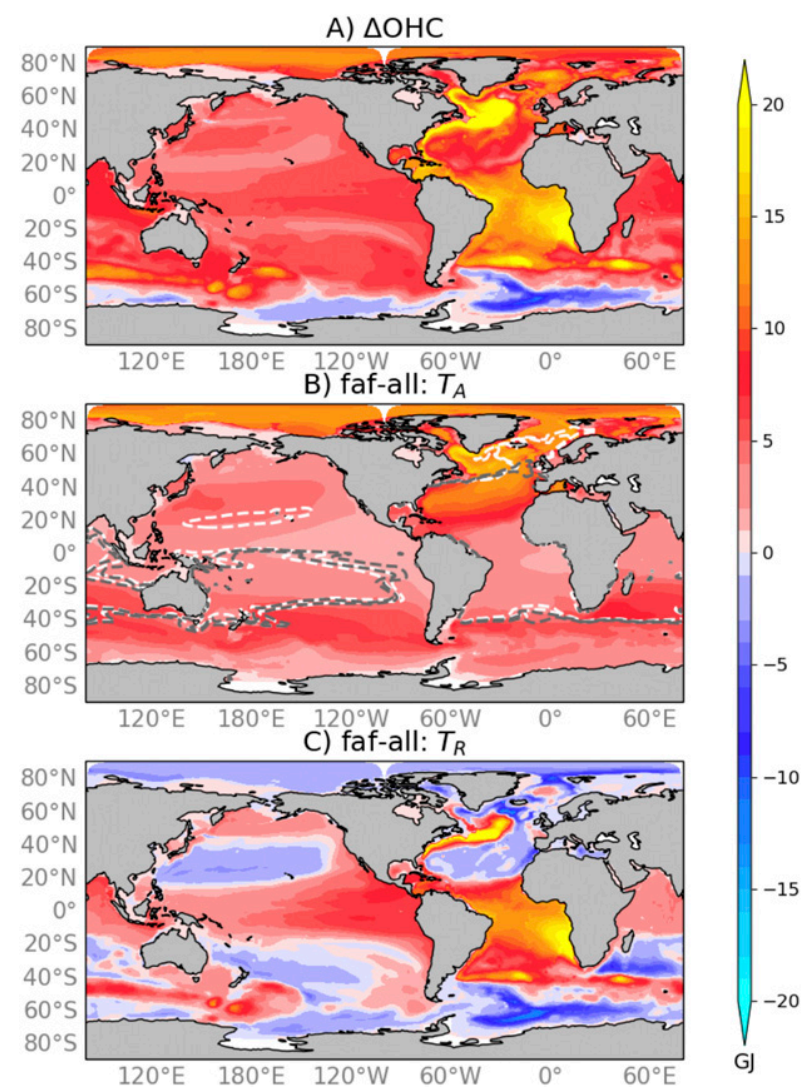

FIG. 2. Time-mean (years 61-80), full depth vertically integrated (a) ocean heat content anomaly, (b) added heat content anomaly, and (c) redistributed heat content anomaly (GJ), for the faf-all experiment. The subtropical front in the Southern Ocean is characterized by the $11^{\circ} \mathrm{C}$ isotherm at $150 \mathrm{~m}$ (white dashed line is for the control run, gray dashed line is for faf-all) in (b), as defined by Nagata et al. (1988).

mixed layers, SRT transports heat downward and counterbalances upward heat transport associated with subsurface cooling from CON, SUB, and nonlocal KPP processes, as a result of surface heat loss, particularly from mid- to high latitudes. In the ocean interior regime, the SRT recirculates recently formed cold, dense waters (bottom, deep, intermediate, and mode waters) - that is, transports heat upward-which is balanced by downward transport due to small-scale mixing from DIA with adjacent waters.

\section{Global and regional ocean heat and storage}

The spatial pattern of depth-integrated OHC anomalies in faf-all (Fig. 2a) shows warming everywhere, except in the Southern Ocean south of $60^{\circ} \mathrm{S}$, where heat is lost to the atmosphere-a result of the increased Antarctic Bottom Water formation in response to changes in the westerlies (Gregory et al. 2016, Fig. 9a). The Atlantic gains more heat (per unit volume) than the Pacific and Indian basins. The North Atlantic has a strong passive warming pattern with a contribution from redistribution along the Gulf Stream path (Figs. 2b,c), associated with AMOC weakening (from $14-15$ to $3-4 \mathrm{~Sv}$ by the end
TABLE 3. Relative contribution of added and redistributed heat to depth-integrated ocean heat storage.

\begin{tabular}{lcc}
\hline \multicolumn{1}{c}{ Subregion } & Added & Redistributed \\
\hline Global & $67 \%$ & $33 \%$ \\
Tropics $\left(20^{\circ} \mathrm{S}-20^{\circ} \mathrm{N}\right)$ & $35 \%$ & $65 \%$ \\
Southern Ocean $\left(35^{\circ}-50^{\circ} \mathrm{S}\right)$ & $75 \%$ & $25 \%$ \\
\hline
\end{tabular}

of 80 years; not shown). The South Atlantic has a remarkable redistributed pattern, adding to the Atlantic basin-average warming. Overall, three redistribution features (Table 3) are noteworthy: 1) OHS along the tropics in all basins $\left(20^{\circ} \mathrm{S}-20^{\circ} \mathrm{N}\right)$; 2) OHS along the Subtropical Front (STF) in the midlatitude Southern Ocean $\left(35^{\circ}-50^{\circ} \mathrm{S}\right)$, especially in the Atlantic and Indian sectors; and 3) OHS at subpolar North Atlantic. Since the AMOC slowdown has been extensively investigated (e.g., Xie and Vallis 2012; Garuba and Klinger 2016), below we focus on the drivers and mechanisms for redistributed OHS in cases 1 and 2.

\section{a. Changes in surface heat fluxes}

$\mathrm{OHC}$ changes occur in response to perturbations in the net surface heat flux $Q_{+} ; Q_{+}$can be divided into a passive contribution $F$ and a surface heat flux feedback driven by changes in the ocean circulation $\Delta Q$ [Eq. (1)]. The partitioning of the temperature field into added and redistributed heat tracers allows the changes in ocean circulation to affect the SST and regulates the surface heat fluxes via redistributed heat. A comparison of the net surface heat flux in the control and perturbed experiments $\left(Q_{c}\right.$ and $Q_{+}$; Figs. 3a,b) reveals that the surface heat gain at low latitudes is largely reduced, especially in the eastern tropical regions of the Pacific and Atlantic [see Fig. 3d herein and Gregory et al. (2016), their Fig. 2d]. This feature was shown to be a coupled response to tropical warming, in which changes in ocean circulation increase the SST and induce cooling surface fluxes (Garuba et al. 2018, their Figs. 2j,k).

The difference in the net surface heat flux between the control and faf-all experiments also shows an increase in surface heat loss along the ACC path, particularly in the Atlantic and Indian sectors (Fig. 3d). Under the control state, surface heat loss occurs both in the WBCs and in the STF along the northern flank of the ACC (Fig. 3a), south of $30^{\circ} \mathrm{S}$ (white for control and gray for faf-all contours in Fig. 2b). Changes in the ACC due to FAFMIP perturbations include a poleward displacement of the STF largely due to wind stress changes, especially in the Atlantic and Indian sectors (Figs. 3c,d, and section 4). The tropics is dominated by redistribution $(65 \%)$ and the midlatitude Southern Ocean has significant passive and redistributed contributions, the latter being stronger in the Atlantic and the Indian Ocean (Figs. $1 b$ and 3b,d).

The subpolar North Atlantic exhibits a large decrease in surface heat loss (Fig. 3b). First, the FAFMIP heat perturbation $F$ induces strongly positive anomalies (Fig. 1b), which means reduction of surface heat loss, essential to formation of denser deep waters. As in previous studies, a weaker AMOC causes cooler SST that enhances the positive heat flux anomaly 


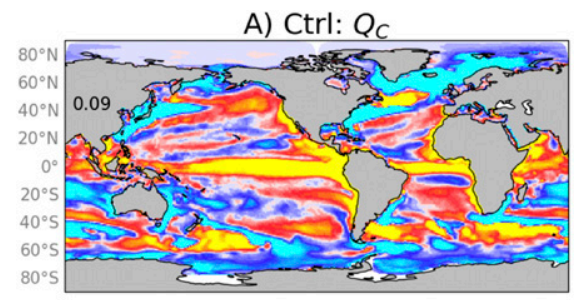

C) faf-stress: $Q_{+}=\Delta Q$

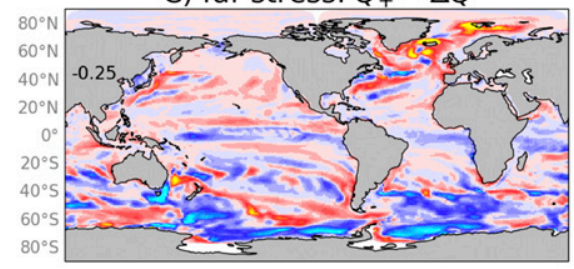

E) faf-water: $Q_{+}=\Delta Q$

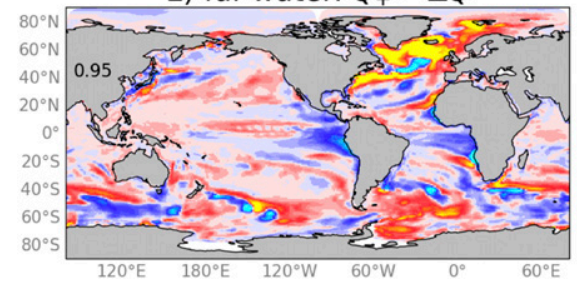

B) faf-all: $Q_{+}=\Delta Q+F$

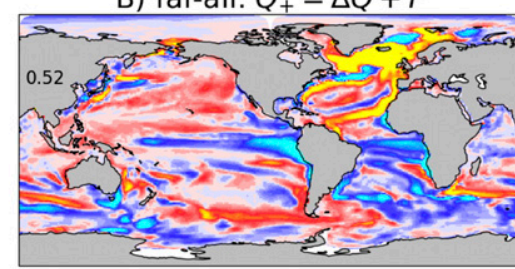

D) faf-all: $\Delta Q$

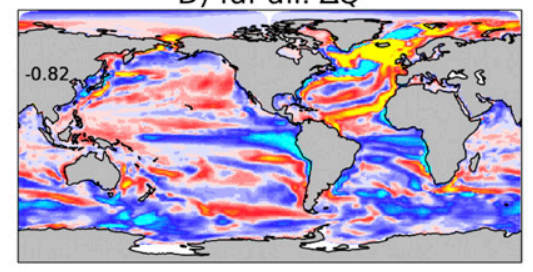

F) faf-heat: $\Delta Q$

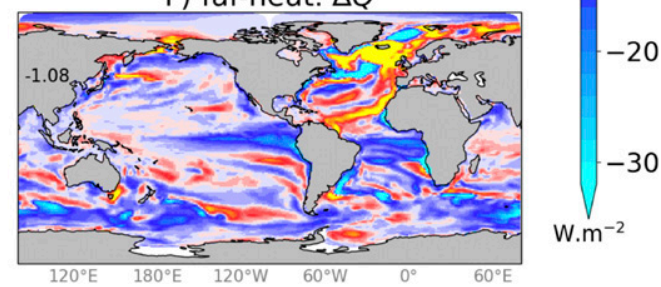

FIG. 3. Time mean (years 61-80) of the surface heat fluxes $\left(\mathrm{W} \mathrm{m}^{-2}\right)$ : (a) net surface heat flux in the control run $Q_{c}$; (b) total surface heat flux anomaly in faf-all $Q_{+}$; (c) redistributed surface heat flux feedback $\Delta Q$ in faf-stress; (d) redistributed surface heat flux feedback $\Delta Q$ in faf-all; (e) redistributed surface heat flux feedback $\Delta Q$ in fafwater; and (f) redistributed surface heat flux feedback $\Delta Q$ in faf-heat. The global mean heat input is show in the topleft corner for each field.

by nearly doubling it (Gregory et al. 2016; Garuba and Klinger 2016), allowing more heat to enter the ocean along with deeper penetration (Xie and Vallis 2012). This effect arises via contributions from faf-all, faf-heat, and faf-water (Figs. 3d-f), all where AMOC weakens (not shown).

While only the FAFMIP heat perturbation contributes to $F$, the redistributed surface feedback $\Delta Q$ is caused by changes in ocean circulation that can result from changes in surface heat, freshwater, and/or momentum fluxes. The $\Delta Q$ values for the individual experiments (faf-stress, faf-water, and faf-heat) are presented in Figs. $3 \mathrm{c}, 3 \mathrm{e}$, and 3 f. The reduced heat gain at low latitudes $\left(15^{\circ} \mathrm{S}-\right.$ $\left.5^{\circ} \mathrm{N}\right)$ is caused by heat redistribution due to surface heat and freshwater flux anomalies. In the midlatitude Southern Ocean $\left(35^{\circ}-\right.$ $50^{\circ} \mathrm{S}$ ), all three individual experiments contribute significantly to the redistributed heat flux. In the next section, we explore the connection between changes in the surface heat fluxes and in OHT processes, which will ultimately drive OHS.

\section{b. Changes in ocean heat transport}

To investigate how OHT is affected under the $2 \mathrm{xCO} 2$ scenario, we first show results for the quasi-steady state (control run) using the SRT framework (section 2c). The depth of the mixed layer regime varies regionally but can reach $700 \mathrm{~m}$ in the midlatitude Southern Ocean and $2000 \mathrm{~m}$ in the subpolar North Atlantic. Dias et al. (2020) suggested that for the depthintegrated budget, from the surface to the bottom of the mixed layer, the net surface heat flux is balanced by the SRT
(Fig. 4a), obscuring the effects from mixed layer physics (KPP, SUB, CON) that effectively propagate the surface fluxes downward into the water column. Due to the vertical redistribution of these mixed layer processes, the opposite contributions at the uppermost layer and at subsurface cancel each other when integrated vertically (Tamsitt et al. 2016). For example, cooling throughout the mixed layer by the nonlocal KPP shows a warming effect in the surface layer and a cooling effect from subsurface to the bottom of the mixed layer. As CON, KPP, and SUB are locally counterbalanced by SRT within deep mixed layers, the associated depth-integrated budget (down to $2000 \mathrm{~m}$ to include the effect of the North Atlantic) is approximated by

$$
Q \approx \mathrm{SRT},
$$

assuming a steady state in the control experiment (i.e., negligible heat tendency), as shown in Fig. 4a. This approximation also holds for all perturbed experiments and tracers $\left(\theta_{p}, T_{R}\right.$, $T_{A}$; Figs. 4b-d), despite some imbalance from the residual between the net surface heat flux and SRT, manifested in the heat tendencies due to passive and redistributed warming:

$$
\begin{aligned}
& \operatorname{NET}\left(\theta_{p}\right) \approx \Delta Q+F-\operatorname{SRT}\left(\theta_{p}\right), \\
& \operatorname{NET}\left(T_{R}\right) \approx \Delta Q-\operatorname{SRT}\left(T_{R}\right), \\
& \operatorname{NET}\left(T_{A}\right) \approx F-\operatorname{SRT}\left(T_{A}\right) .
\end{aligned}
$$



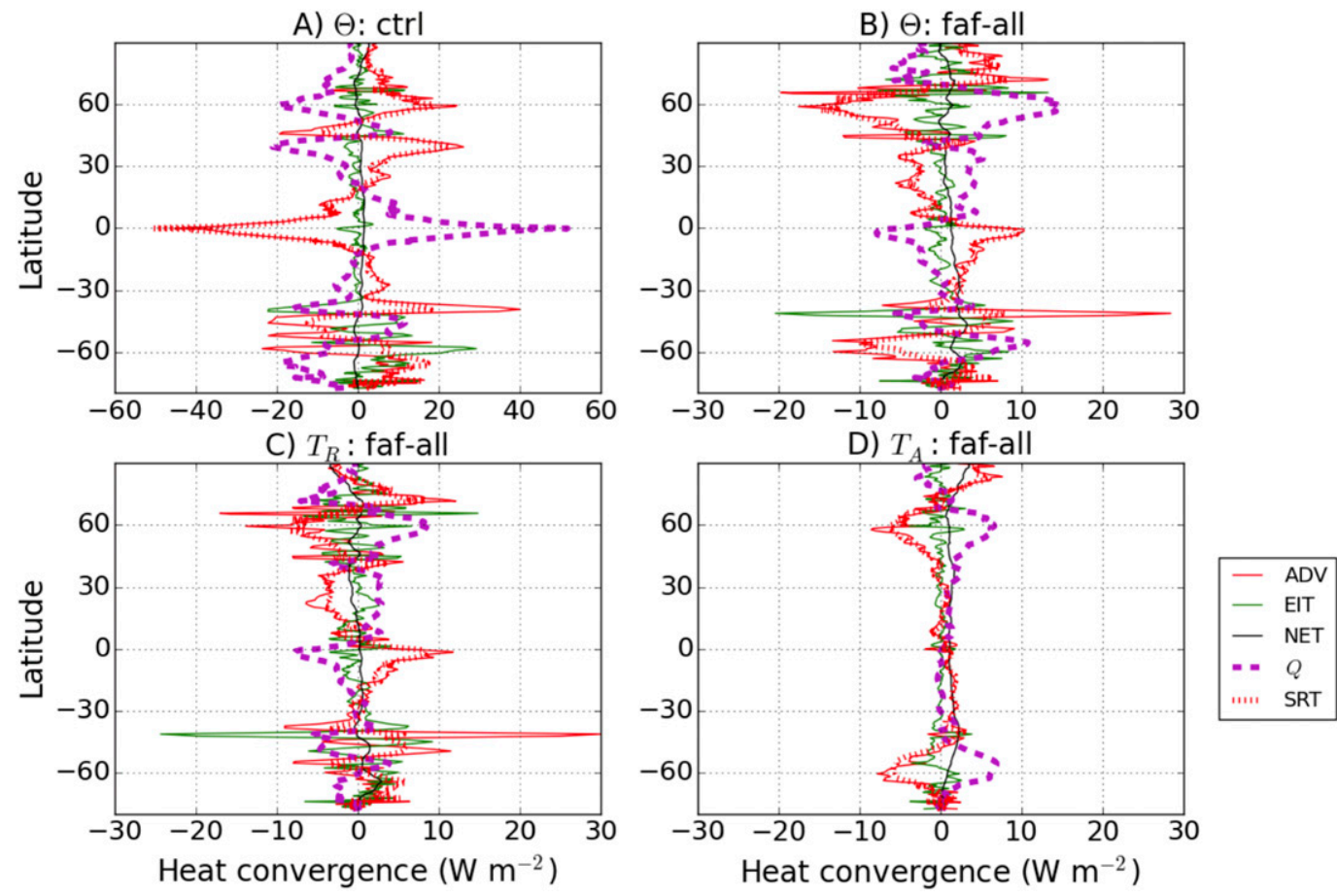

FIG. 4. Time-mean (years 61-80), zonally and vertically integrated (from surface to $2000 \mathrm{~m}$ ) heat budget (W m ${ }^{-2}$ ) for (a) the control run (conservative temperature $\theta ; Q=Q_{c}$ ), (b) faf-all (conservative temperature $\theta$; $Q=\Delta Q+F$, where $\Delta Q=Q_{p}-Q_{c}$ ), (c) faf-all (redistributive temperature $T_{R} ; Q=\Delta Q$ ), and (d) faf-all (added temperature $T_{A}$; $Q=F)$. Note that the $x$ axis varies between panels, given the heat fluxes in the control run are larger than the anomalies in faf-all experiment.

The net added heat tendency (Fig. 5a), integrated from 10 to $2000 \mathrm{~m}$, shows that heat is stored at midlatitudes of both hemispheres $\left(20^{\circ}-60^{\circ}\right)$, at high latitudes of the North Atlantic, and in the Arctic. Mixed layer processes (KPP, SUB, CON) and DIA propagate the surface heat flux perturbation $F$ downward within deep mixed layer regions (cf. Fig. 1b and Figs. 5b,c). Part of this heat is stored locally and part recirculates into the subtropical gyres via SRT (Fig. 5d). The zonal structure (Fig. 6) reveals that subsurface warming due to mixed layer and DIA processes only occur at deep mixed layers (Figs. 6c,f,i), while anomalies associated with SRT (Figs. 6b,e,h) propagate down and equatorward along the subduction pathways (heat tendencies following isopycnals in Figs. 6a,d,g).

Changes in OHT due to redistribution above $2000 \mathrm{~m}$ are shown in Fig. 7. Most of the changes at low latitudes, subtropical gyres, and within the midlatitude Southern Ocean are explained by SRT changes, suggesting that the redistributed OHS is driven primarily by changes in ocean circulation (large and mesoscale) rather than changes in vertical mixing. Redistribution causes cooling at subtropical gyres and warming at tropical latitudes. Heat is transported equatorward via EBCs (e.g., the Canary and Benguela Currents) to equatorial currents (North and South Equatorial Currents) and stored at those tropical latitudes (see section 4), resulting in warmer SSTs and inducing a cooling feedback in the air-sea heat flux (Fig. 3d). Along the ACC, changes in the STF position and current transport drive heat redistribution, particularly in the Atlantic and Indian sectors (Fig. 2c).

The North Atlantic has a similar pattern of changes to other subtropical gyres, although substantially stronger, probably due to subpolar changes arising from the AMOC slowdown. In contrast, the South Atlantic subtropical gyre shows heat gain rather than loss due to redistribution, associated with a rearrangement of the basin circulation (Fig. 7d), as explained in section 4. The WBC of the South Atlantic, the Brazil Current, becomes stronger (Pontes et al. 2016) and transports more heat poleward. Its northern counterparts, the North Brazil and Guiana Currents, largely weaken though (section 4). Part of this heat reenters the South Atlantic basin through gyre circulation via the EBC (and is further carried out to the tropics), and the other part converges at STF to be advected eastward by the ACC, contributing to the OHS in the midlatitude Southern Ocean (Figs. 7a,d). As the ACC accelerates and shifts poleward (Figs. 3a,d), the SRT drives redistributed OHS along the STF, explaining $25 \%$ of the midlatitude Southern Ocean warming band (e.g., Kuhlbrodt and Gregory 2012).

The zonally integrated structure of the redistributed heat budget reveals further details of the mechanisms that lead to redistributed OHS (Fig. 8). Between 1000 and 2000 m, redistributed OHS arises from the strong reduction of North Atlantic Deep Water (NADW) formation (positive anomalies in Fig. 8f), associated with AMOC weakening in response to 


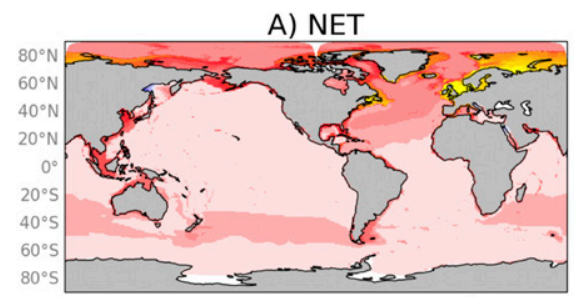

C) $\mathrm{KPP}+\mathrm{SUB}+\mathrm{CON}$

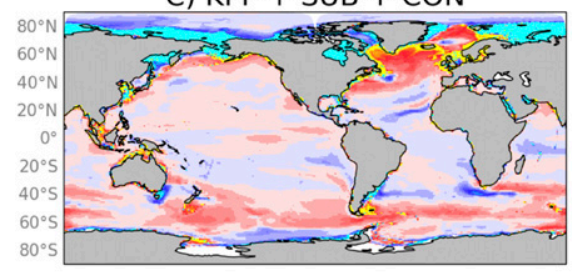

E) EIT

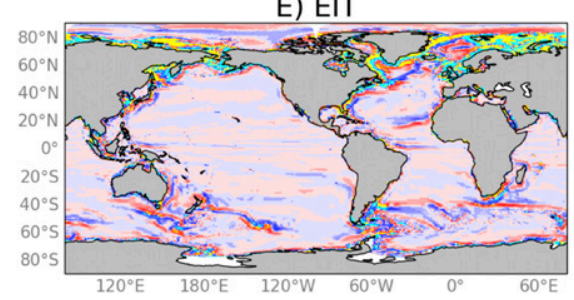

B) DIA

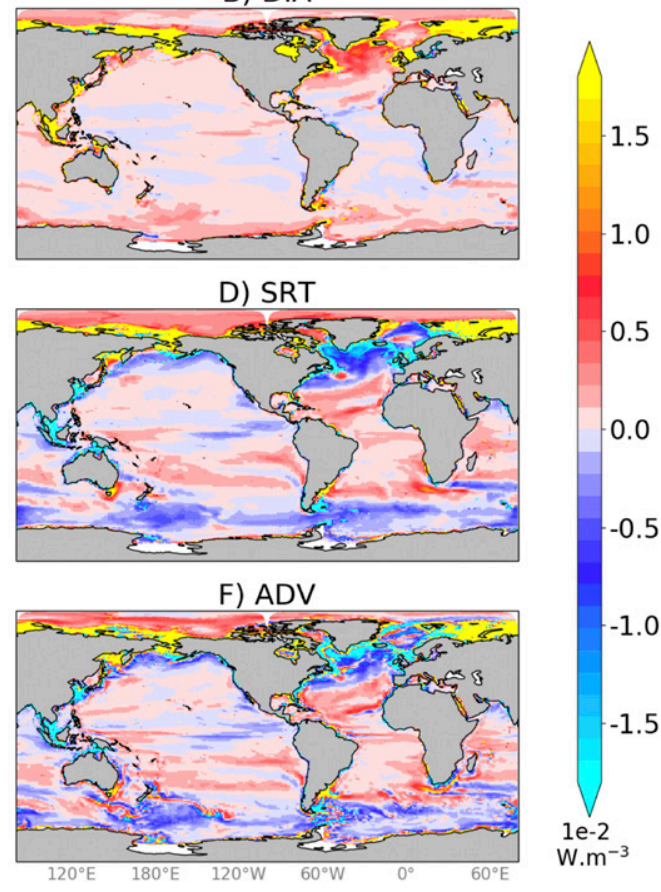

FIG. 5. Time mean (years 1-80) of the faf-all simulation $\left(\mathrm{W} \mathrm{m}^{-3}\right)$, showing added heat convergence vertically integrated over 10-2000 $\mathrm{m}$ for (a) net tendency (NET), (b) dianeutral diffusion (DIA), (c) mixed layer processes (KPP, SUB, CON), (d) super-residual transport (SRT), (e) eddy-induced transport (EIT), and (f) mean advection $(\mathrm{ADV})$.

decreasing surface heat loss (Banks and Gregory 2006). Reduction of dense water formation causes warming below $1000 \mathrm{~m}$ (Fig. 8d). Above $1000 \mathrm{~m}$, changes include heat loss in the subtropical gyres $\left(20^{\circ}-40^{\circ}\right.$, except in the South Atlantic) and heat gain in the tropics $\left(20^{\circ} \mathrm{S}-20^{\circ} \mathrm{N}\right)$ due to redistribution (Figs. 8a,d,g), in contrast with the passive warming in the subtropical gyres (Figs. 6a,d,g). Isopycnals sink at tropical and subtropical latitudes, indicating expansion in the volume of subtropical $(24.6<$ $\left.\sigma_{\theta}<26.6 \mathrm{~kg} \mathrm{~m}^{3}\right)$ and subpolar $\left(26.6<\sigma_{\theta}<27.0 \mathrm{~kg} \mathrm{~m}^{3}\right)$ mode waters-an overall lightening of the upper ocean.

\section{Ocean circulation changes}

Below we investigate mechanisms of heat redistribution. Focusing on the tropics and in the midlatitude Southern Ocean, we evaluate changes in the SRT and upper-ocean stratification to understand which changes in ocean circulation drive redistributed OHS. Although these two regions were previously related to passive heat storage (Banks and Gregory 2006; Xie and Vallis 2012; Morrison et al. 2016; Armour et al. 2016), both regions have an important contribution from the redistributed component due to changes in ocean circulation in this study, similarly to that found by Garuba and Klinger (2018) and H. Chen et al. (2019).

Poleward heat transport in both oceans and atmosphere is essential to maintain the Earth's energy balance, as radiative heat is gained at low latitudes and lost at high latitudes (Seidov 2009). The large-scale meridional OHT due to the SRT circulation is shown in Fig. 9a. In the mean state, the poleward
OHT in both hemispheres is generally similar to observations and reanalyses (Trenberth and Caron 2001; Ganachaud 2003), although ACCESS-OM2 has weaker transport at low latitudes than observations (Kiss et al. 2020). In response to FAFMIP perturbations, the poleward OHT substantially reduces (increases) in the Northern (Southern) Hemisphere, governed by changes in the Atlantic (Fig. 9a). The individual FAFMIP experiments reveal that the faf-heat perturbation dominates the changes in the meridional OHT (Fig. 9b); faf-stress has a significant contribution to the changes in both hemispheres and a primary role in the changes south of $20^{\circ} \mathrm{S}$; and the faf-water perturbation induces negligible changes in poleward OHT.

The response of the ocean circulation is more complex than the changes in meridional OHT (Fig. 10), mainly because circulation changes vary among subtropical gyres and among WBCs and EBCs. In general, the SRT heat transport integrated over the upper $1000 \mathrm{~m}$ increases across equatorial regions, EBCs and ACC, but it has a variable response in WBCs, dependent on basin. In the North Atlantic, a noticeable deepening of the shallow isopycnals reflects an increased upper-ocean stratification due to surface heat input from $F$ (Figs. 11c,f). OHT weakens at all depths in the North Atlantic Current (NAC) whereas it strengthens at the surface and weakens at middepth in the subtropical gyre (Fig. 10). The depth-integrated SRT heat transport reduces along the Gulf Stream path but increases along the Canary and North Equatorial Currents. Changes in the North Atlantic subtropical gyre and associated OHT reduction (Fig. 9a) suggest that 


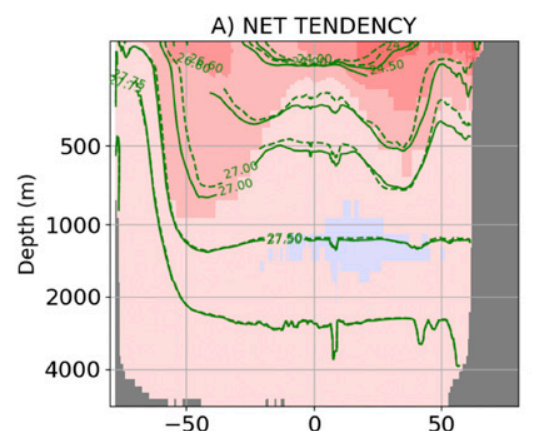

D) NET TENDENCY

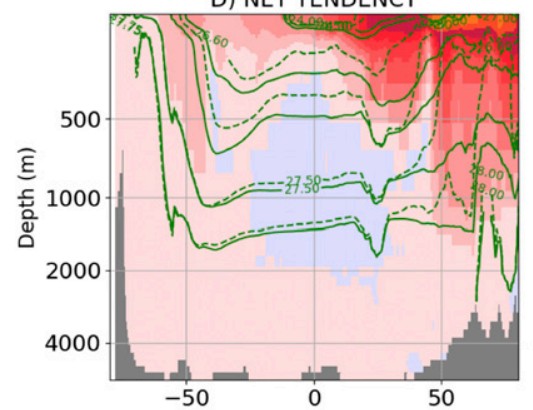

G) NET TENDENCY

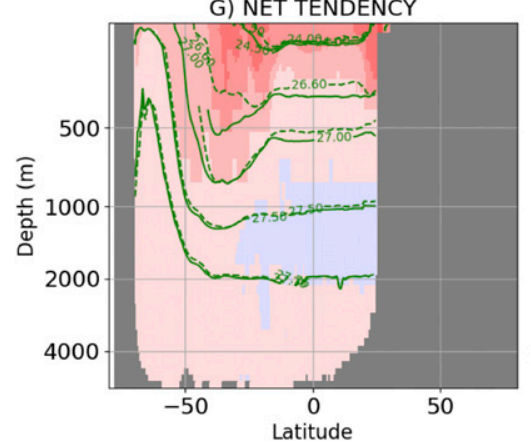

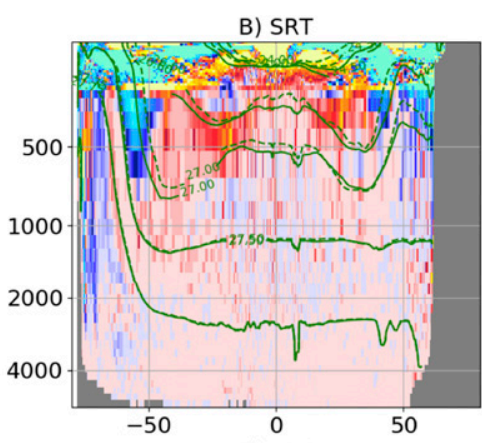

E) SRT

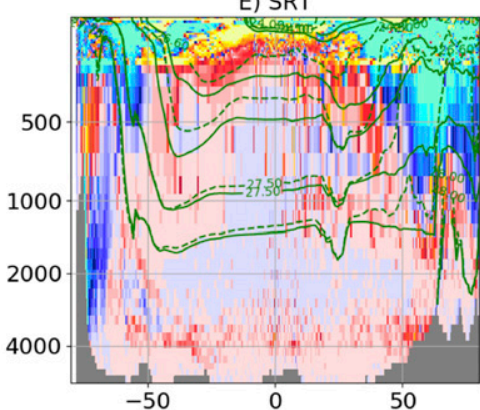

H) SRT

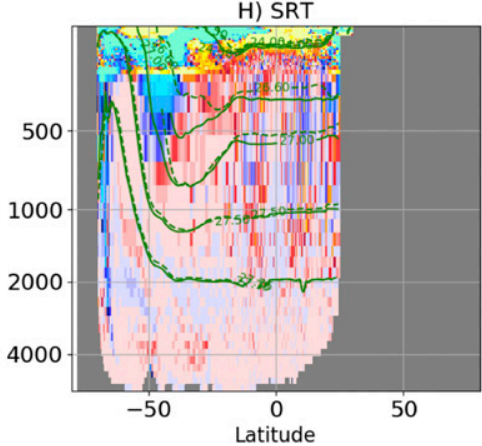

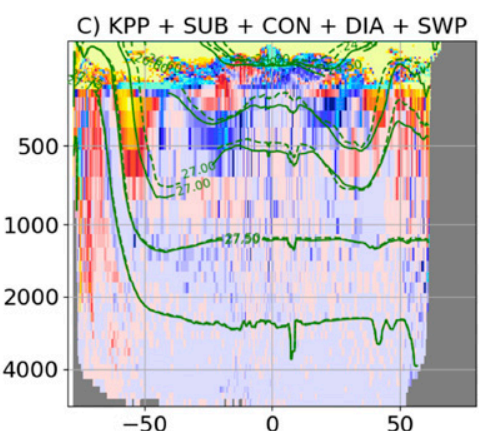
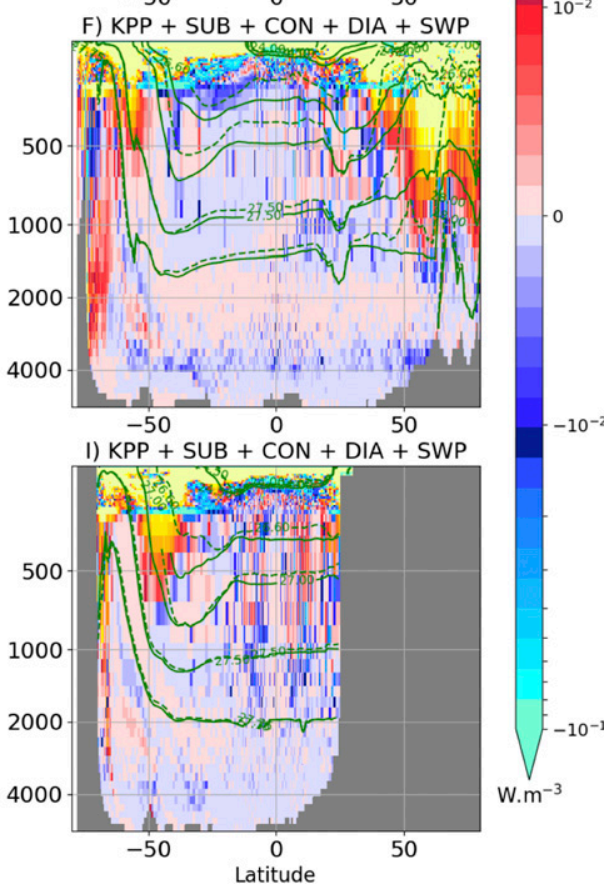

FIG. 6. Time mean (years 1-80) of the faf-all simulation $\left(\mathrm{W} \mathrm{m}^{-3}\right)$, showing added heat convergence zonally integrated per basin for the (top) Pacific, (middle) Atlantic, and (bottom) Indian Ocean. Shown are (a),(d),(g) net added heat tendency, (b),(e),(h) super-residual transport (SRT), and (c),(f),(i) mixed layer and dianeutral processes. Green contours are isopycnals separating major water masses [following Table 4 in Dias et al. (2020)], for control (dashed) and faf-all (solid) experiments. The color bar is presented in symmetrical logarithmic scale to highlight the heat convergence anomalies in the ocean interior, which are significantly smaller than those near the surface.

heat moving poleward with the Gulf Stream/NAC reduces, and the extra heat, stored passively in the gyres, is transported equatorward via EBCs and equatorial currents (Fig. 10). Changes in stratification and circulation agree with recent results that documented a decoupling between the surface and subsurface gyre circulation due to increased stratification (G. Wang et al. 2015; Li et al. 2019). Similar changes, with increased stratification and upper-ocean subtropical gyre acceleration (and slowdown in the lower thermocline), are also observed in the Pacific and the Indian Ocean. On the other hand, the stratification in the tropics largely weakens, where redistributed OHS is striking (Fig. 11c). The intensification of the equatorial currents at surface and subsurface should transport extra heat both westward and eastward via the complex system of equatorial currents and countercurrents (Fig. 10).

Changes in the South Atlantic subtropical gyre are distinct to the changes in other basins. OHT associated with the Brazil
Current intensifies at surface and at depth, contributing to the poleward OHT in the Southern Hemisphere (Fig. 9a). In the South Atlantic, a shift from equatorward OHT in the control state to poleward OHT in faf-all results from both 1) an intensification of the Brazil Current and 2) a slowdown of the Deep WBC (which carries cold water poleward at $2500 \mathrm{~m}$; Fig. 10e; e.g., Pontes et al. 2016; Meinen et al. 2017), ultimately resulting in increased heat convergence at the STF. This effect is reinforced by the larger heat flux anomalies along the northern flank of the ACC and translates into a reduction in stratification along the STF (Figs. 11c,f). Both mechanisms result in strong redistributed $\mathrm{OHC}$ at the $\mathrm{STF}\left(35^{\circ}-45^{\circ} \mathrm{S}\right.$, Fig. 7). Although the intensification and poleward shift of the ACC is expected due to wind stress changes, the faf-stress experiment results in very little redistributed OHS within the ACC (not shown). Changes between faf-all and faf-heat, however, suggest that wind stress changes play a key role in 


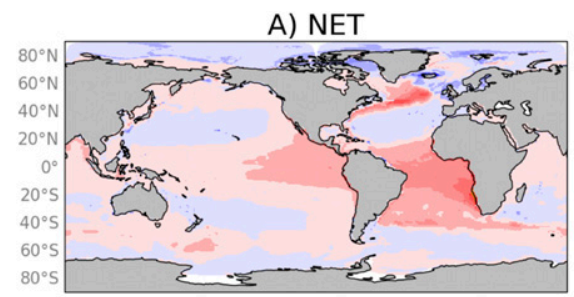

C) $\mathrm{KPP}+\mathrm{SUB}+\mathrm{CON}$

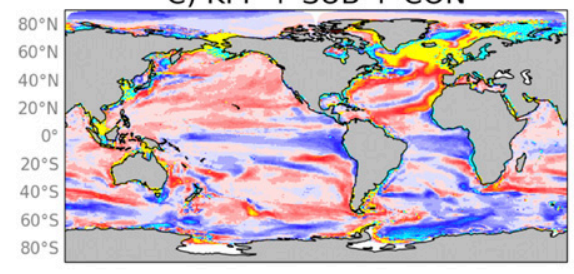

E) EIT

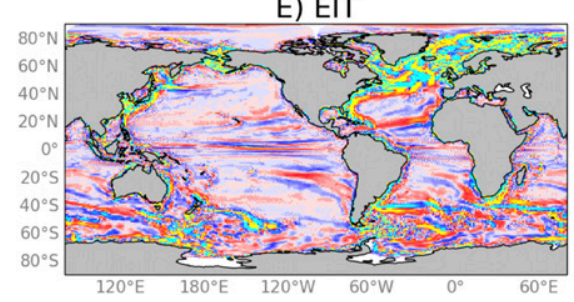

B) $\mathrm{DIA}+\mathrm{SWP}$

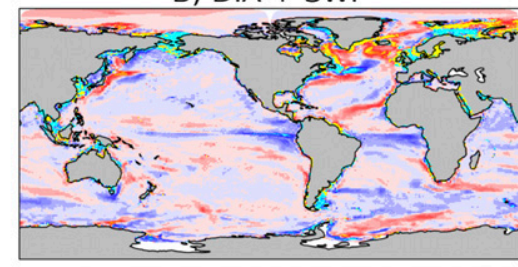

D) SRT

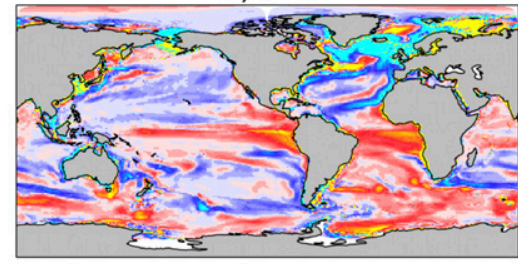

F) ADV

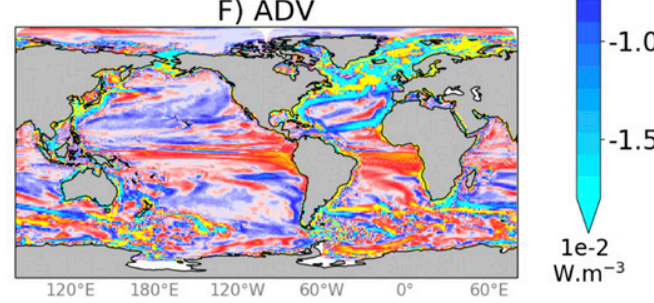

$-1.5$

$-1.0$

0.5

$-0.0$

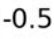

.5
1.0

FIG. 7. Time mean (years 1-80) of the faf-all simulation $\left(\mathrm{W} \mathrm{m}^{-3}\right)$, showing redistributed heat convergence vertically integrated over 10-2000 $\mathrm{m}$ for (a) net tendency (NET), (b) dianeutral diffusion plus shortwave penetration (DIA and SWP), (c) mixed layer processes (KPP, SUB, CON), (d) super-residual transport (SRT), (e) eddyinduced transport (EIT), and (f) mean advection (ADV). the spatial pattern of redistributed heat, as also found in Garuba and Klinger (2018) and H. Chen et al. (2019).

\section{Discussion}

Ocean heat storage was decomposed into added and redistributed components in $2 \mathrm{xCO} 2$ scenarios simulated with ACCESS$\mathrm{OM} 2$, and their relative roles analyzed from a process-based perspective. Most of the OHS occurs in the top $2000 \mathrm{~m}$ and north of $60^{\circ} \mathrm{S}$. Added heat (Fig. 5a) enters at midlatitudes driven by Ekman convergence and is passively advected along ventilation pathways (Figs. 6a,d,g; e.g., Banks and Gregory 2006; Garuba and Klinger 2016; H. Chen et al. 2019). Redistributed heat is dominated by circulation changes (Fig. 7a) associated with the super-residual component, with a minor contribution from changes in vertical mixing (section 3b). Redistribution is important in three regions: 1) low latitudes $\left.\left(20^{\circ} \mathrm{S}-20^{\circ} \mathrm{N}\right), 2\right)$ the midlatitude $\left(35^{\circ}-50^{\circ} \mathrm{S}\right)$ Southern Ocean, and 3) the subpolar North Atlantic. As the link between AMOC slowdown and faster and deeper penetration of OHS due to redistribution has received a lot of attention (Xie and Vallis 2012; Winton et al. 2013; Garuba and Klinger 2016), we focused on the mechanisms causing OHS in the tropics and in the midlatitude Southern Ocean.

The redistributed OHS pattern has important differences between basins. In the North Atlantic, Pacific, and south Indian Ocean subtropical gyres, redistributed cooling is associated with SRT changes (Figs. 8b,e,h). Increased gyre stratification (Fig. 11c) leads to intensified surface heat transport via eastern boundary currents (EBCs) and WBCs (Fig. 10b), and slowdown in the transport of WBCs (Fig. 10d), culminating in OHS at tropical latitudes. The magnitude of the changes in ocean heat transport (OHT) varies among gyres and causes a larger OHS in the Atlantic, followed by the east Pacific, and a small storage in the Indian Ocean (Figs. 2c and 7a).

Redistribution of heat in the South Atlantic subtropical gyre is unique compared to other basins. Although reduced upperocean stratification (Figs. 11c,f) is associated with stronger OHT in the Benguela Current, as seen in other EBCs, the WBC transport by the Brazil Current increases at both surface and middepths (Figs. 10a-d). Distinct changes in the South Atlantic gyre circulation contribute to a larger OHS in the tropical Atlantic than in the Pacific and Indian, a strong hemispheric asymmetry, and a larger heat convergence in the STF. Redistributed heat contributes together with added heat to OHS across midlatitudes of the Southern Ocean (Figs. 2b,c).

OHS in the tropics arises from circulation changes in the subtropical gyres, from where intensified EBCs redistribute heat to zonal equatorial currents. Although some studies suggested that OHS in the shallow tropical thermocline is predominantly passive (Banks and Gregory 2006; Xie and Vallis 2012), our results highlight the primary role of the redistribution component, where its feedback causes local surface heat loss (Garuba et al. 2018; see also Fig. 3d herein). We demonstrate how the regional OHT is modified in a climate change scenario and how the super-residual framework (Dias et al. 2020) proved useful to identify changes in water mass formation (e.g., decrease of dense water formation, resulting in 

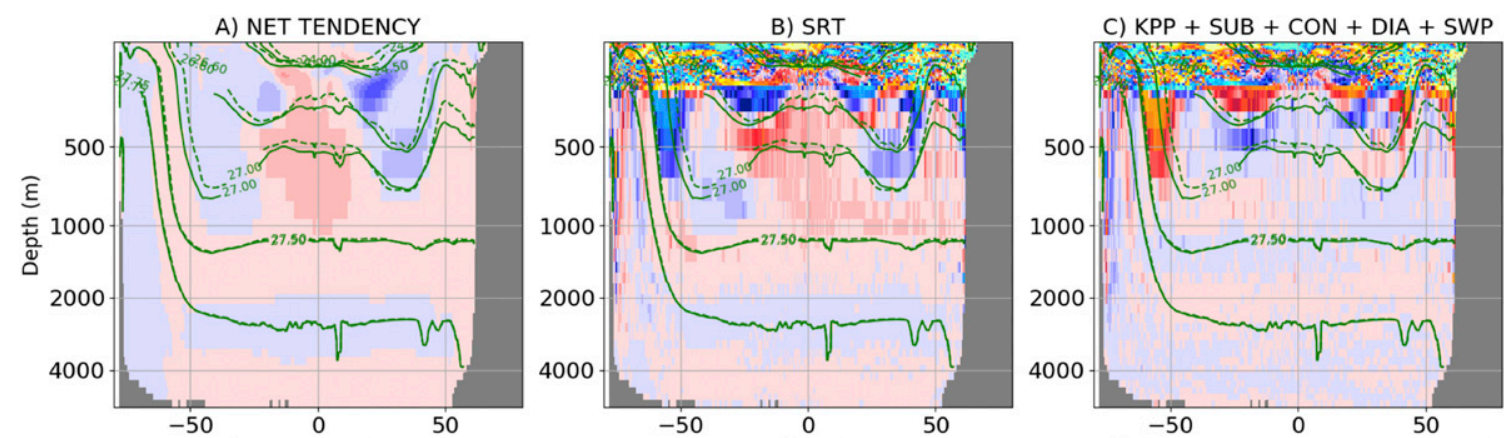

D) NET TENDENCY
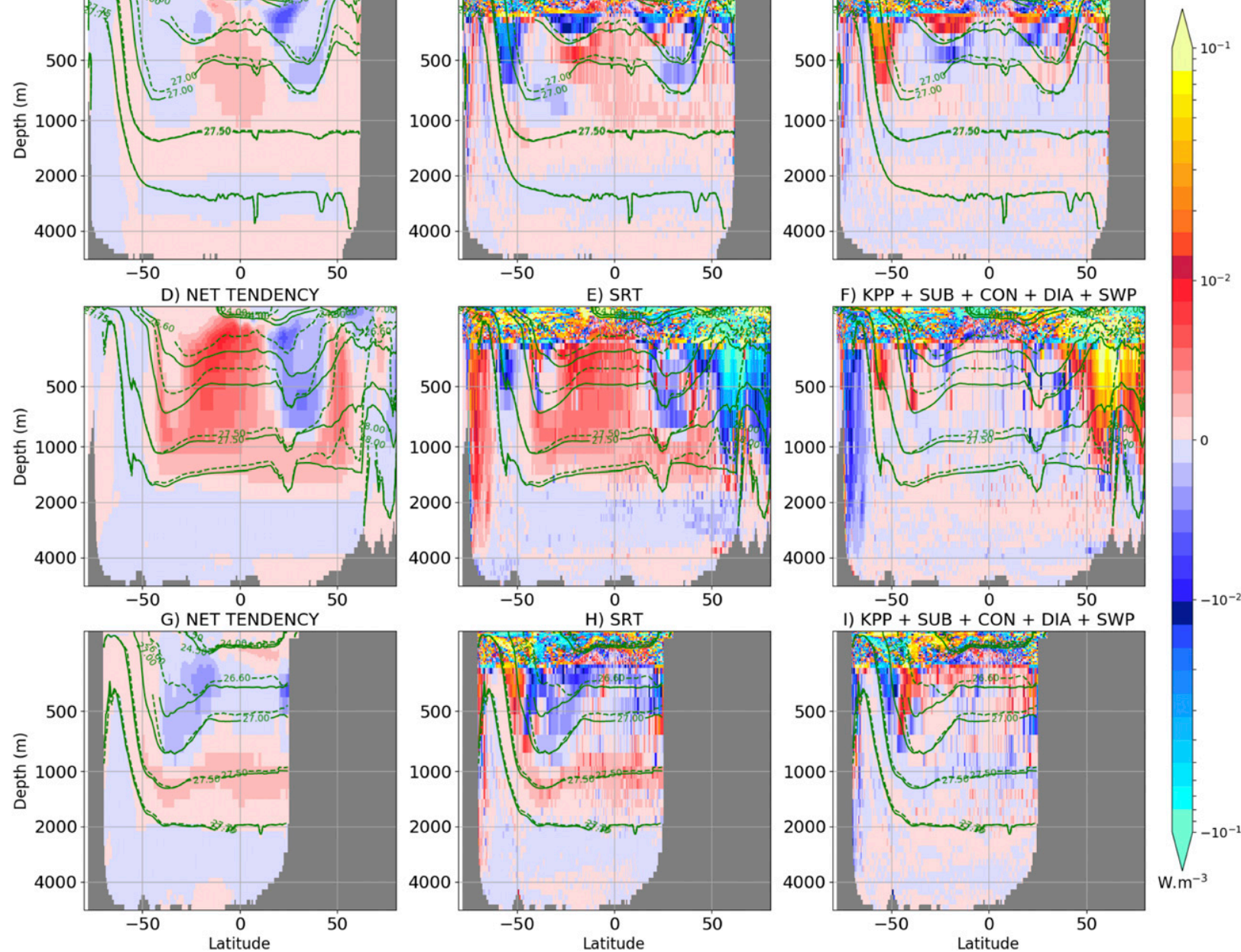

FIG. 8. Time mean (years 1-80) of the faf-all simulation $\left(\mathrm{W} \mathrm{m}^{-3}\right)$, showing redistributed heat convergence zonally integrated per basins for the (top) Pacific, (middle) Atlantic, and (bottom) Indian Ocean, showing (a),(d),(g) net redistributed heat tendency, (b),(e),(h) super-residual transport (SRT), and (c),(f),(i) mixed layer and dianeutral processes. Green contours are isopycnals separating major water mass [following Table 4 in Dias et al. (2020)] for control (dashed) and faf-all (solid) experiments. The color bar is presented in symmetrical logarithmic scale to highlight the heat convergence anomalies in the ocean interior, which are significantly smaller than those near the surface.

positive anomalies of vertical processes between 1000 and $2000 \mathrm{~m}$; Figs. 8c,f) and the pathways of heat redistribution in the ocean interior (i.e., heat advected away from mixed layers by the SRT; Figs. 8b,e). In subtropical and tropical regions, the SRT dominates the redistribution of heat, being only weakly offset by vertical mixing processes.

In addition to the distinct response in the South Atlantic, we note stronger changes in the North Atlantic compared to other subtropical gyres. The Gulf Stream largely weakened at subsurface due to changes in the AMOC, consistent with previous studies (Yang et al. 2016; C. Chen et al. 2019). Similar studies that investigated changes in the subtropical gyres under climate change also emphasized changes in WBCs. All WBCs (except the Gulf Stream) are expected to intensify and to shift poleward (Yang et al. 2016, 2020; Qu et al. 2019), with a larger warming trend over the WBCs than globally (Wu et al. 2012). G. Wang et al. (2015) suggested that an increase in the stratification (Luo et al. 2018) strengthens the barrier between the upper and lower circulation due to the baroclinic nature of the gyres, and thereby results in acceleration at near surface and slowdown in the lower thermocline. Subsequently, Li et al. (2019) showed that the thermal warming effect dominates the stratification response relative to wind stress changes. Our results support these findings, and also highlight that both the Gulf Stream and Brazil Current behave differently from other WBCs due to the AMOC weakening, and its effect on the circulation of the subtropical gyres.

The response of EBCs has had less attention than their WBC counterparts. EBCs are shallower and weaker than WBCs, and most climate change studies have focused on their coastal upwelling (Demarcq 2009; Gutiérrez et al. 2011; Barton et al. 2013; Sydeman et al. 2014). Some studies suggested that the surface warming trend in the open ocean is opposite to the trends nearshore (Santos et al. 2012), and also that the 

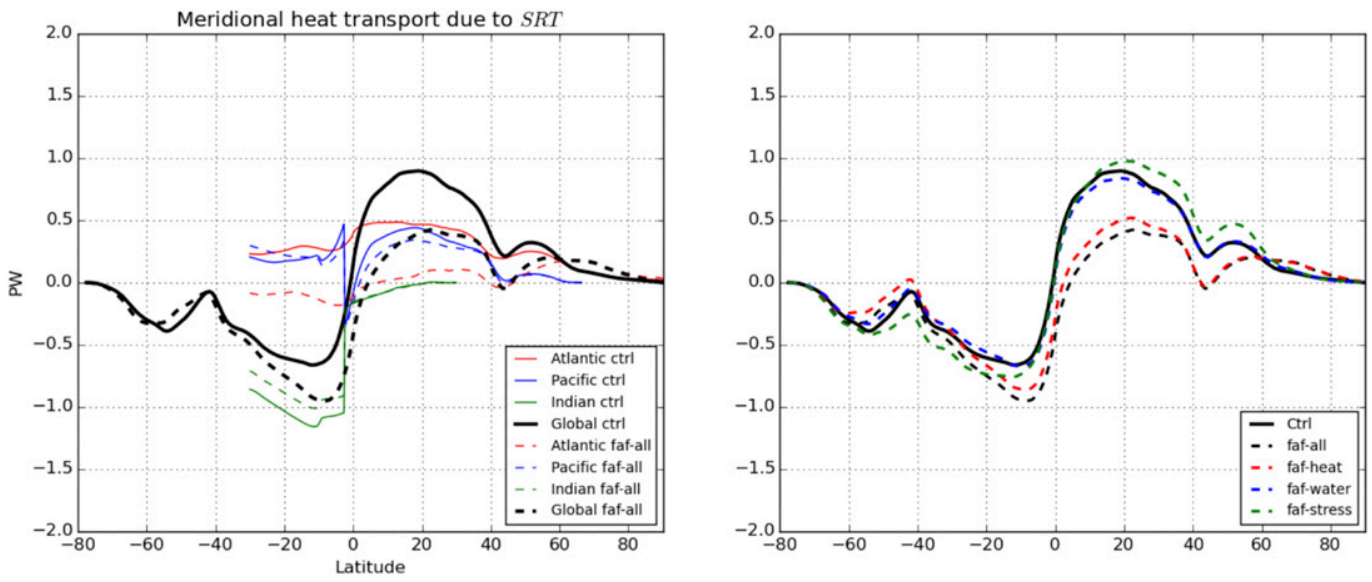

FIG. 9. Time-mean (years 61-80) meridional heat transport (PW; $1 \mathrm{PW}=10^{15} \mathrm{~W}$ ) due to the super-residual transport (SRT). (a) Global and basins meridional heat transport for the control (continuous line) and faf-all (dashed) simulation. (b) Global meridional heat transport for control (continuous black line) and FAFMIP experiments: faf-all (black dashed), faf-heat (red dashed), faf-water (blue dashed), and faf-stress (green dashed).

poleward expansion of the Hadley cells would increase upwelling at the poleward end and decrease it equatorward (Rykaczewski et al. 2015; D. Wang et al. 2015). However, the spatiotemporal limitations of observations and superimposed interannual to multidecadal variability, along with the limited ability of global climate models to represent well the EBCs, makes it difficult to project the impacts of climate change on their upwelling systems (Bakun et al. 2015; García-Reyes et al. 2015).

While projections indicate increasing global mean stratification in the upper $200 \mathrm{~m}$ (Gruber 2011; Yamaguchi and Suga 2019), trends in EBCs have not been properly evaluated [although Brochier et al. (2013) found that the Humboldt Current might stratify under climate change]. In spite of the stratifying tendency observed over most of the subtropical gyres and global ocean (Fig. 11c), our results indicate an opposite trend in tropical regions, specifically in the eastern Pacific and Atlantic basins, where a reduction of the upper-ocean stratification and a large redistributed OHS occurs. The asymmetric response of both stratification and redistributed OHS is likely due to interhemispheric differences in the connection between northern and southern subtropics and the tropical region, where the South Atlantic/Pacific gyres have a more direct pathway than the northern gyres (Strub et al. 2013).

Tropical warming is a robust feature in observed SST patterns (Xie et al. 2010), such as an El Niño-like structure in the east Pacific (Vecchi and Wittenberg 2010; Luo et al. 2015). Recent results have emphasized the role of equatorial regions for the global OHT (Holmes et al. 2019). Garuba et al. (2018) showed that tropical warming plays an important role in the redistributed OHS, resulting in heat release to the atmosphere under a coupled system, and the large efficacy of this mechanism is the main driver of reduced climate sensitivity. The thermal gradient between the east and west tropical Pacific has been shown to have a time-dependent response, where the warming in the east dominates the slow multidecadal changes (Held et al 2010; Andrews et al. 2015). While high-latitude heat uptake is partially compensated by heat release at low latitudes ( $\Delta Q$ in Fig. 3d) due to redistribution (Winton et al. 2013), our results show how redistribution of heat from the subtropical gyres (where passive warming takes place) to the tropical regions (where redistributed heat storage takes places) develops through an interplay of changes in wind-driven circulation and upper-ocean stratification.

The Southern Ocean is a key region for the heat uptake and storage during the past 15 years (Roemmich et al. 2015; Wijffels et al. 2016) and in climate change scenarios (Kuhlbrodt and Gregory 2012). In various studies, passive warming makes an important contribution to midlatitude Southern Ocean heat storage (Armour et al. 2016; Gregory et al. 2016; Morrison et al. 2016), where heat uptake around $45^{\circ}-60^{\circ} \mathrm{S}$ results in OHS centered at $45^{\circ} \mathrm{S}$ (Fig. 4d). Part of the heat is added locally by vertical mixing processes (Figs. $1 \mathrm{~b}$ and $5 \mathrm{~b}, \mathrm{c}$ ), while the SRT stores heat slightly equatorward, in the northern boundary of the ACC (Fig. 5d). Our process-based results add new insights on the processes involved in the pattern of Southern Ocean heat storage in climate change scenarios.

Intensification and southward displacement of the STF cause substantial redistribution of heat, contributing to midlatitude Southern Ocean storage (Fig. 7a). A consistent shift in the ACC fronts is not clear from observational studies (Shao et al. 2015; Freeman et al. 2016). CMIP5 models do not have a clear correlation between meridional shift in winds and in the ACC (Meijers et al. 2012) but some studies indicate that wind stress is not the only driver of front position (Graham et al. 2012; De Boer et al. 2013). Changes in westerlies tend to strengthen the northward Ekman drift and tilt isopycnals (Lowe and Gregory 2006; Frankcombe et al. 2013; Bouttes and Gregory 2014; Kuhlbrodt et al. 2015; Marshall et al. 2015; Saenko et al. 2015), which are partially compensated by eddies (Böning et al. 2008; Farneti and Delworth 2010; Downes and Hogg 2013; Farneti et al. 2015). Coarse models, however, have limited representation of this effect (Griffies et al. 2015). Our results show a nonnegligible poleward shift of the STF 

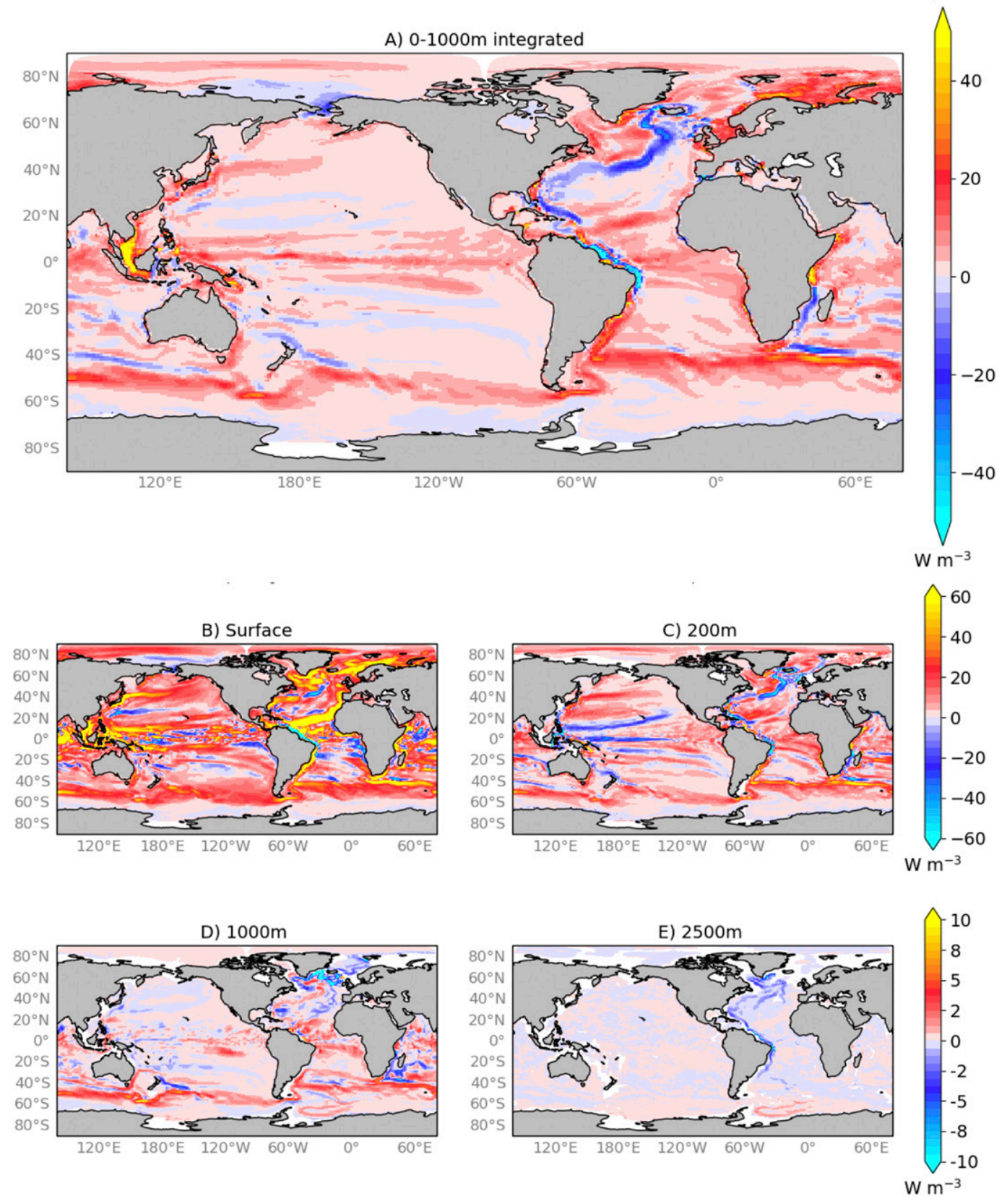

FIG. 10. Time-mean (years 61-80) faf-all anomaly $\left(\mathrm{W} \mathrm{m}^{-3}\right)$ with respect to the control run, average heat transport due to SRT: (a) depth-integrated 0-1000 m, (b) at surface $(k=1),(\mathrm{c})$ at $200 \mathrm{~m},(\mathrm{~d})$ at $1000 \mathrm{~m}$, and (e) at $2500 \mathrm{~m}$.

(Fig. 2b), which contributes to heat redistribution (Fig. 2c). Strengthening of the Brazil Current also contributes to the larger heat convergence along the STF (Fig. 10a), and all surface flux perturbations are important for redistribution (Figs. 3c,e,f).

Our budget analyses reveal that the SRT explains most of the redistribution of heat, with only a small contribution from vertical mixing processes. Redistributed heat storage has a significant contribution to the storage in the midlatitude Southern Ocean, although smaller than passive warming (Fig. 2, Table 3). In contrast with the earlier assumption that heat storage could be approximated by passive processes (Church et al. 1991; Jackett et al. 2000), our results reinforce recent findings on the importance of the redistribution component (e.g., Banks and Gregory 2006; Xie and Vallis 2012; Garuba and Klinger 2016; Garuba et al. 2018; H. Chen et al. 2019).

Studies with OGCMs (Armour et al. 2016; Huber and Zanna 2017; Jansen et al. 2018) show similar large-scale heat uptake patterns under climate change as in AOGCMs (e.g., Gregory et al. 2016). OGCMs are cheaper to run than AOGCMs and can use surface-atmospheric forcing products that are continuously updated (Tsujino et al. 2018), thus reducing biases 

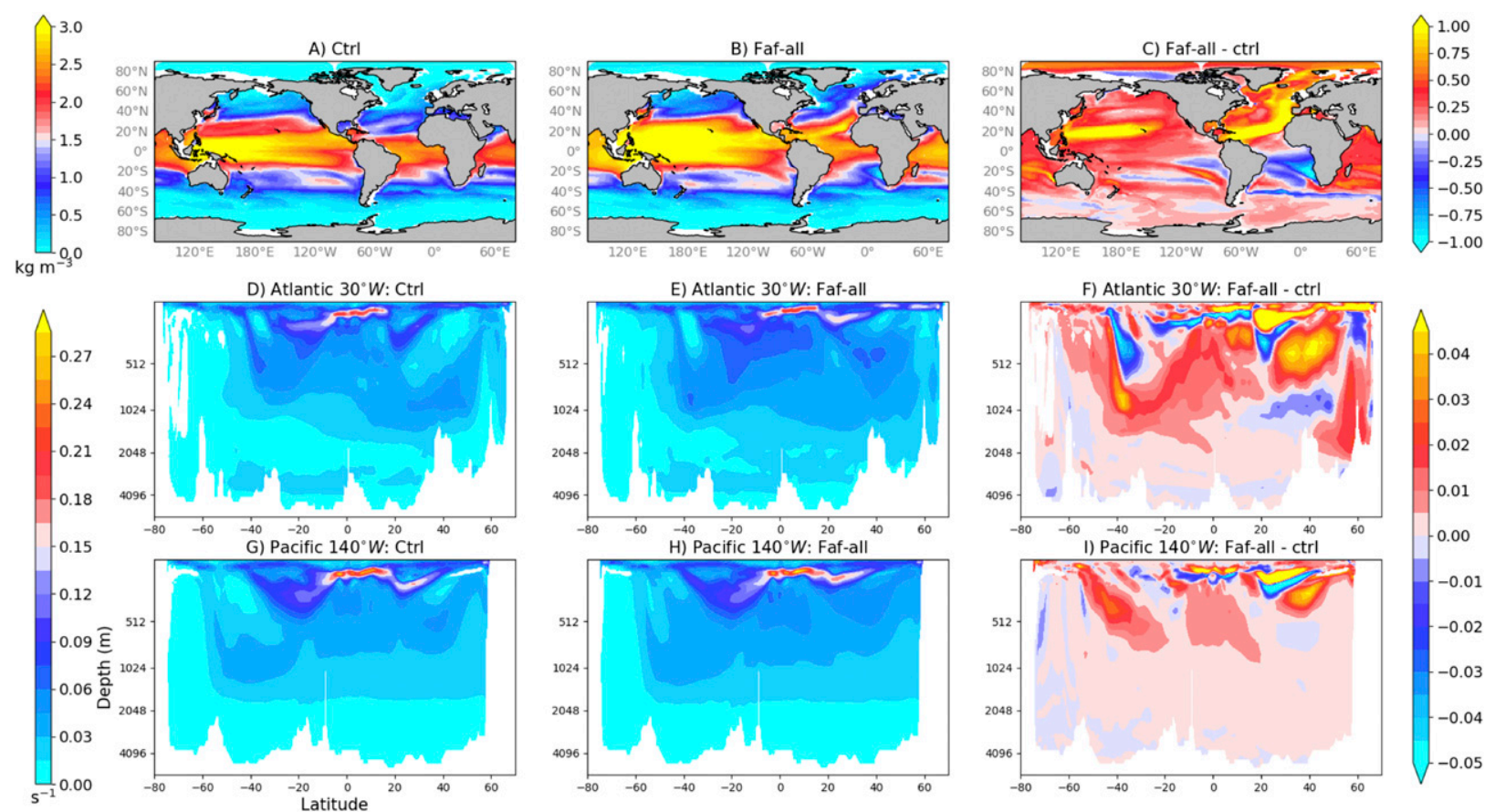

FIG. 11. (top) Time-mean (years 61-80) stratification $\left(\mathrm{kg} \mathrm{m}^{-3}\right)$ estimated as the difference between potential density at the surface and $300 \mathrm{~m}([\mathrm{~S}=$ $\rho_{300 \mathrm{~m}}-\rho_{\text {surface }}$, for (a) control, (b) faf-all, and (c) faf-all minus control. (middle),(bottom) The Brunt-Väisälä frequency ( $\mathrm{s}^{-1}$ ) for a zonal transect in the Atlantic Ocean $\left(30^{\circ} \mathrm{W}\right)$ and Pacific Ocean, respectively, for (d),(g) control, (e),(h) faf-all, and (f),(i) faf-all minus control.

associated with the atmospheric component of AOGCMs (e.g., the position of westerly winds is realistically represented in JRA55-do). Although the FAFMIP tracer design for AOGCMs allows a truly coupled atmosphere-ocean-driven redistribution feedback (Gregory et al. 2016) we can only allow ocean-driven redistribution feedback in this OGCM study, represented through bulk formulas. The redistribution feedback from AOGCMs makes an important contribution to the AMOC slowdown, but a comparatively smaller contribution to circulation changes in other regions (Todd et al. 2020). Nevertheless, we note similar qualitative changes in total $\mathrm{OHC}$ (including both added and redistributed components) to those shown in recent work using FAFMIP experimental protocols (Gregory et al. 2016; Todd et al. 2020).

One caveat associated with OGCMs is the requirement for SSS restoring (Griffies et al. 2009; Danabasoglu et al. 2014), which affects the surface freshwater fluxes and the sensitivity to freshwater perturbations. Our experimental design applies a similar approach to Zika et al. (2018) and Todd et al. (2020) to prescribe air-sea fluxes, but with an important difference. In the aforementioned studies, all surface fluxes are prescribed in flux form, while here only fluxes associated with the salinity restoring are prescribed, and turbulent fluxes are calculated through bulk formulas. Our approach allows some air-sea feedbacks due to the bulk formulas (and also longwave radiation) dependence on the ocean state, and permits the sea ice to evolve in response to ocean changes, relevant to high-latitude processes (e.g., Pellichero et al. 2018), while the approach used in Todd et al. (2020) for OGCMs requires an inactive sea ice model, as ocean-sea ice fluxes are prescribed (A. Blaker 2019, personal communication). Despite the different experimental design, depth-integrated added and redistributed $\mathrm{OHC}$ changes are qualitatively similar (Todd et al. 2020, their Figs. 6 and 7; see also Figs. 2b,c herein).

Model biases in state-of-the-art climate and ocean models can influence heat uptake and redistribution, which is highly dependent on the ventilation pathways (e.g., Katavouta et al. 2019). For example, limitations in the representation of thermal fronts finer than the model grid are well-known biases among coarse-resolution models (Griffies et al. 2009; Bi et al. 2013; Richter 2015). Models tend to overestimate the winter mixed layer depth in the Southern Ocean (Downes et al. 2015; Kiss et al. 2020) compared with observations (Dong et al. 2008; Schmidtko et al. 2013; Buongiorno Nardelli et al. 2017) due to limitations in the surface buoyancy forcing (Sallée et al. 2013) and/or subgrid-scale parameterization (Dufresne et al. 2013; Wenegrat et al. 2018). As a result, excessive subduction of mode waters can drive a warming bias at around 700-m depth (Griffies et al. 2009; Bi et al. 2013; Dias et al. 2020), although its impact on the ventilation of heat and carbon is currently unknown (Kiss et al. 2020). Part of this bias is considered by results when presenting perturbed anomalies to the mean state. Nevertheless, an extreme response of the simulated mixed layer will likely result in differences from a more realistic climate system. We expect high-resolution models to have smaller warming biases in the mean state (Griffies et al. 2015), but the effect on the relative contribution to added and redistributed Southern Ocean heat storage is still not clear.

\section{Conclusions}

This study highlights the importance of ocean heat storage due to heat redistribution, which primarily results from ocean circulation changes at large scale and mesoscale by the super-residual 
transport (Kuhlbrodt et al. 2015; Dias et al. 2020). Changes in vertical mixing are secondary. At midlatitudes and in subtropical gyres, heat is added locally and redistributed to the tropics. Redistribution of heat accounts for $65 \%$ of the tropical warming, associated with increased gyre stratification and equatorward heat transport, especially via EBCs, causing redistribution (oceandriven) feedback (Garuba and Klinger 2016). Heat redistribution contributes to $25 \%$ of the heat storage in the midlatitude Southern Ocean, driven by increased heat convergence as a result of the strengthening and poleward shift of the front, in addition to substantial passive warming in the midlatitude Southern Ocean (Armour et al. 2016; Morrison et al. 2016; Garuba et al. 2018; C. Chen et al. 2019). Our findings based on ocean-only simulations might differ quantitatively from fully coupled models. Further studies are required to quantify differences, and particularly the significance of the redistribution feedback to ocean heat storage in the tropics and Southern Ocean.

These results enhance our understanding of ocean heat uptake, transport, and storage, and have implications for global mean and regional sea level changes (Church et al. 2013). Process-based studies such as carried out in this study and others (e.g., Palter et al. 2014; Exarchou et al. 2015; Griffies et al. 2015) are important to refine models and therefore to reduce spread in sea level projections, which largely depend on the efficiency with which heat is sequestered by the ocean (Kuhlbrodt and Gregory 2012). In individual model studies such as this, we can explore the details of ocean heat transport and storage at global and regional scales to establish a baseline for future intermodel comparisons, as process-based diagnostics become available in CMIP6 (Griffies et al. 2016; Gregory et al. 2016). Earlier sea level estimates (Church et al. 1991; Jackett et al. 2000) and recent global OHC reconstructions (Zanna et al. 2019) have considered ocean heat storage as a passive process. Our study adds to the growing evidence (Banks and Gregory 2006; Xie and Vallis 2012; Gregory et al. 2016; Garuba and Klinger 2016, 2018; Garuba et al. 2018; H. Chen et al. 2019) that redistribution of heat makes an important contribution to ocean heat storage over longer multidecadal time scales.

Acknowledgments. This work was supported by the Australian Research Council (ARC) Discovery Grant DP160103130, ARC Centre of Excellence for Climate Extremes (CE170100023), and the National Computational Infrastructure through the National Computational Merit Allocation Scheme. FBD and AS were supported by a Tasmanian Graduate Research Scholarship and CSIRO-UTAS Quantitative Marine Science top-up. FBD was supported by the Academy of Finland (Project 322432). RF, SJM, and SRR were supported by the Earth Systems and Climate Change Hub of the Australian Government's National Environmental Science Program. SRR was jointly supported by the Australian Antarctic Program Partnership and by the Centre for Southern Hemisphere Ocean Research, a partnership between CSIRO and the Qingdao National Laboratory for Marine Science and Technology (QNLM). CMD was supported by an ARC Future Fellowship FT130101532. CMD, LC and ELMD were supported by the Natural Environment Research Council NE/P019293/1. MMM was supported by the Brazilian Research Council $\mathrm{CNPq}$ research
Grant 306896/2015-0. We are thankful for the support from the Consortium for Ocean-Sea Ice Modelling in Australia (COSIMA), and for the reviewers' comments that greatly helped to improve the quality of the manuscript.

\section{REFERENCES}

Andrews, T., J. M. Gregory, and M. J. Webb, 2015: The dependence of radiative forcing and feedback on evolving patterns of surface temperature change in climate models. J. Climate, 28, 1630-1648, https://doi.org/10.1175/JCLI-D-14-00545.1.

Armour, K. C., J. Marshall, A. Donohoe, and E. R. Newsom, 2016: Southern Ocean warming delayed by circumpolar upwelling and equatorward transport. Nat. Geosci., 9, 549-554, https:// doi.org/10.1038/ngeo2731.

Bakun, A., B. A. Black, S. J. Bograd, M. García-Reyes, A. J. Miller, R. R. Rykaczewski, and W. J. Sydeman, 2015: Anticipated effects of climate change on coastal upwelling ecosystems. Curr. Climate Change Rep., 1, 85-93, https://doi.org/10.1007/s40641-015-0008-4.

Banks, H. T., and J. M. Gregory, 2006: Mechanisms of ocean heat uptake in a coupled climate model and the implications for tracer based predictions of ocean heat uptake. Geophys. Res. Lett., 33, L07608, https://doi.org/10.1029/2005GL025352.

Barton, E. D., D. B. Field, and C. Roy, 2013: Canary Current upwelling: More or less? Prog. Oceanogr., 116, 167-178, https:// doi.org/10.1016/j.pocean.2013.07.007.

Bi, D., and Coauthors, 2013: ACCESS-OM: The ocean and sea-ice core of the ACCESS coupled model. Aust. Meteor. Oceanogr. $J .$, 63, 213-232, https://doi.org/10.22499/2.6301.014.

Böning, C. W., A. Dispert, M. Visbeck, S. R. Rintoul, and F. U. Schwarzkopf, 2008: The response of the Antarctic Circumpolar Current to recent climate change. Nat. Geosci., 1, 864-869, https://doi.org/10.1038/ngeo362.

Bouttes, N., and J. M. Gregory, 2014: Attribution of the spatial pattern of $\mathrm{CO}_{2}$-forced sea level change to ocean surface flux changes. Environ. Res. Lett., 9, 034004, https://doi.org/10.1088/ 1748-9326/9/3/034004.

Brochier, T., V. Echevin, J. Tam, A. Chaigneau, K. Goubanova, and A. Bertrand, 2013: Climate change scenarios experiments predict a future reduction in small pelagic fish recruitment in the Humboldt Current system. Global Change Biol., 19, 18411853, https://doi.org/10.1111/gcb.12184.

Buongiorno Nardelli, B., S. Guinehut, N. Verbrugge, Y. Cotroneo, E. Zambianchi, and D. Iudicone, 2017: Southern Ocean mixed-layer seasonal and interannual variations from combined satellite and in situ data. J. Geophys. Res. Oceans, 122, 10 042-10 060, https://doi.org/10.1002/2017JC013314.

Cazenave, A., and Coauthors, 2018: Global sea-level budget 1993present. Earth Syst. Sci. Data, 10, 1551-1590, https://doi.org/ 10.5194/essd-10-1551-2018.

Chen, C., G. Wang, S.-P. Xie, and W. Liu, 2019: Why does global warming weaken the Gulf Stream but intensify the Kuroshio? J. Climate, 32, 7437-7451, https://doi.org/10.1175/JCLI-D-18-0895.1.

Chen, H., A. K. Morrison, C. O. Dufour, and J. L. Sarmiento, 2019: Deciphering patterns and drivers of heat and carbon storage in the Southern Ocean. Geophys. Res. Lett., 46, 3359-3367, https://doi.org/10.1029/2018GL080961.

Church, J. A., J. S. Godfrey, D. R. Jackett, and T. J. McDougall, 1991: A model of sea level rise caused by ocean thermal expansion. J. Climate, 4, 438-456, https://doi.org/10.1175/15200442(1991)004<0438:AMOSLR>2.0.CO;2.

- D. Monselesan, J. M. Gregory, and B. Marzeion, 2013: Evaluating the ability of process based models to project sea-level 
change. Environ. Res. Lett., 8, 014051, https://doi.org/10.1088/ 1748-9326/8/1/014051.

Danabasoglu, G., and Coauthors, 2014: North Atlantic simulations in Coordinated Ocean-ice Reference Experiments phase II (CORE-II). Part I: Mean states. Ocean Modell., 73, 76-107, https://doi.org/10.1016/j.ocemod.2013.10.005.

De Boer, A. M., R. M. Graham, M. D. Thomas, and K. E. Kohfeld, 2013: The control of the Southern Hemisphere westerlies on the position of the subtropical front. J. Geophys. Res. Oceans, 118, 5669-5675, https://doi.org/10.1002/jgrc.20407.

Demarcq, H., 2009: Trends in primary production, sea surface temperature and wind in upwelling systems (1998-2007). Prog. Oceanogr., 83, 376-385, https://doi.org/10.1016/j.pocean.2009.07.022.

Dias, F. B., C. M. Domingues, S. J. Marsland, S. M. Griffies, S. R. Rintoul, R. Matear, and R. Fiedler, 2020: On the superposition of mean advective and eddy-induced transports in global ocean heat and salt budgets. J. Climate, 33, 1121-1140, https:// doi.org/10.1175/JCLI-D-19-0418.1.

Domingues, C. M., J. A. Church, N. J. White, P. J. Gleckler, S. E. Wijffels, P. M. Barker, and J. R. Dunn, 2008: Improved estimates of upper-ocean warming and multi-decadal sea-level rise. Nature, 453, 1090-1093, https://doi.org/10.1038/nature07080.

Dong, S., J. Sprintall, S. T. Gille, and L. Talley, 2008: Southern Ocean mixed-layer depth from Argo float profiles. J. Geophys. Res, 113, C06013, https://doi.org/10.1029/2006JC004051.

Downes, S. M., and A. M. Hogg, 2013: Southern Ocean circulation and eddy compensation in CMIP5 models. J. Climate, 26, 7198-7220, https://doi.org/10.1175/JCLI-D-12-00504.1.

— , and Coauthors, 2015: An assessment of Southern Ocean water masses and sea ice during 1988-2007 in a suite of interannual CORE-II simulations. Ocean Modell., 94, 67-94, https://doi.org/10.1016/j.ocemod.2015.07.022.

Dufresne, J. L., and Coauthors, 2013: Climate change projections using the IPSL-CM5 Earth system model: From CMIP3 to CMIP5. Climate Dyn., 40, 2123-2165, https://doi.org/10.1007/s00382-012-1636-1.

Exarchou, E., T. Kuhlbrodt, J. M. Gregory, and R. S. Smith, 2015: Ocean heat uptake processes: A model intercomparison. J. Climate, 28, 887-908, https://doi.org/10.1175/JCLI-D-14-00235.1.

Eyring, V., S. Bony, G. A. Meehl, C. A. Senior, B. Stevens, R. J. Stouffer, and K. E. Taylor, 2016: Overview of the Coupled Model Intercomparison Project Phase 6 (CMIP6) experimental design and organization. Geosci. Model Dev., 9, 19371958, https://doi.org/10.5194/gmd-9-1937-2016.

Farneti, R., and T. L. Delworth, 2010: The role of mesoscale eddies in the remote oceanic response to altered Southern Hemisphere winds. J. Phys. Oceanogr., 40, 2348-2354, https://oi.org/10.1175/ 2010JPO4480.1.

—_, and Coauthors, 2015: An assessment of Antarctic Circumpolar Current and Southern Ocean meridional overturning circulation during 1958-2007 in a suite of interannual CORE-II simulations. Ocean Modell., 93, 84-120, https://doi.org/10.1016/ j.ocemod.2015.07.009.

Fox-Kemper, B., and Coauthors, 2011: Parameterization of mixed layer eddies. III: Implementation and impact in global ocean climate simulations. Ocean Modell., 39, 61-78, https://doi.org/ 10.1016/j.ocemod.2010.09.002.

Frankcombe, L. M., P. Spence, A. M. Hogg, M. H. England, and S. M. Griffies, 2013: Sea level changes forced by Southern Ocean winds. Geophys. Res. Lett., 40, 5710-5715, https:// doi.org/10.1002/2013GL058104.

Freeman, N. M., N. S. Lovenduski, and P. R. Gent, 2016: Temporal variability in the Antarctic Polar Front (2002-2014). J. Geophys. Res. Oceans, 121, 7263-7276, https://doi.org/10.1002/2016JC012145.
Ganachaud, A., 2003: Large-scale mass transports, water mass formation, and diffusivities estimated from World Ocean Circulation Experiment (WOCE) hydrographic data. J. Geophys. Res., 108, 3213, https://doi.org/10.1029/2002JC001565.

García-Reyes, M., W. J. Sydeman, D. S. Schoeman, R. R. Rykaczewski, B. A. Black, A. J. Smit, and S. J. Bograd, 2015: Under pressure: Climate change, upwelling, and eastern boundary upwelling ecosystems. Front. Mar. Sci., 2, 109, https://doi.org/10.3389/fmars.2015.00109.

Garuba, O. A., and B. A. Klinger, 2016: Ocean heat uptake and interbasin transport of the passive and redistributive components of surface heating. J. Climate, 29, 7507-7527, https:// doi.org/10.1175/JCLI-D-16-0138.1.

- , and - 2018: The role of individual surface flux components in the passive and active ocean heat uptake. J. Climate, 31, 6157-6173, https://doi.org/10.1175/JCLI-D-17-0452.1.

_ J. Lu, F. Liu, and H. A. Singh, 2018: The active role of the ocean in the temporal evolution of climate sensitivity. Geophys. Res. Lett., 45, 306-315, https://doi.org/10.1002/2017GL075633.

Gent, P. R., J. Willebrand, T. J. McDougall, and J. C. McWilliams, 1995: Parameterizing eddy-induced tracer transports in ocean circulation models. J. Phys. Oceanogr., 25, 463-474, https:// doi.org/10.1175/1520-0485(1995)025<0463:PEITTI>2.0.CO;2.

Gnanadesikan, A., R. D. Slater, P. S. Swathi, and G. K. Vallis, 2005: The energetics of ocean heat transport. J. Climate, 18, 26042616, https://doi.org/10.1175/JCLI3436.1.

Graham, R. M., A. M. De Boer, K. J. Heywood, M. R. Chapman, and D. P. Stevens, 2012: Southern Ocean fronts: Controlled by wind or topography? J. Geophys. Res., 117, C08018, https:// doi.org/10.1029/2012JC007887.

Gregory, J. M., 2000: Vertical heat transports in the ocean and their effect on time-dependent climate change. Climate Dyn., 16, 501-515, https://doi.org/10.1007/s003820000059.

- and Coauthors, 2016: The Flux-Anomaly-Forced Model Intercomparison Project (FAFMIP) contribution to CMIP6: Investigation of sea-level and ocean climate change in response to $\mathrm{CO}_{2}$ forcing. Geosci. Model Dev. Discuss., 9, 39934017, https://doi.org/10.5194/gmd-9-3993-2016.

Griffies, S. M., A. Gnanadesikan, R. C. Pacanowski, V. D. Larichev, J. K. Dukowicz, and R. D. Smith, 1998: Isoneutral diffusion in a $z$-coordinate ocean model. J. Phys. Oceanogr., 28, 805-830, https://doi.org/ 10.1175/1520-0485(1998)028<0805:IDIAZC $>2.0 . C O ; 2$.

— Experiments (COREs). Ocean Modell., 26, 1-46, https:// doi.org/10.1016/j.ocemod.2008.08.007.

- and Coauthors, 2015: Impacts on ocean heat from transient mesoscale eddies in a hierarchy of climate models. J. Climate, 28, 952-977, https://doi.org/10.1175/JCLI-D-14-00353.1. -, and Coauthors, 2016: OMIP contribution to CMIP6: Experimental and diagnostic protocol for the physical component of the Ocean Model Intercomparison Project. Geosci. Model Dev. Discuss., 9, 3231-3296, https://doi.org/10.5194/gmd-9-3231-2016.

Gruber, N., 2011: Warming up, turning sour, losing breath: Ocean biogeochemistry under global change. Philos. Trans. Roy. Soc. London, A369, 1980-1996, https://doi.org/10.1098/rsta.2011.0003.

Gutiérrez, D., and Coauthors, 2011: Coastal cooling and increased productivity in the main upwelling zone off Peru since the midtwentieth century. Geophys. Res. Lett., 38, L07603, https:// doi.org/10.1029/2010GL046324.

Held, I. M., M. Winton, K. Takahashi, T. Delworth, F. Zeng, and G. K. Vallis, 2010: Probing the fast and slow components of global warming by returning abruptly to preindustrial forcing. J. Climate, 23, 2418-2427, https://doi.org/10.1175/2009JCLI3466.1. 
Hieronymus, M., and J. Nycander, 2013: The budgets of heat and salinity in NEMO. Ocean Modell., 67, 28-38, https://doi.org/ 10.1016/j.ocemod.2013.03.006.

Holmes, R. M., J. D. Zika, R. Ferrari, A. F. Thompson, E. R. Newsom, and M. H. England, 2019: Atlantic Ocean heat transport enabled by Indo-Pacific heat uptake and mixing. Geophys. Res. Lett., 46,1393913 949, https://doi.org/10.1029/2019GL085160.

Huber, M. B., and L. Zanna, 2017: Drivers of uncertainty in simulated ocean circulation and heat uptake. Geophys. Res. Lett., 44, 1402-1413, https://doi.org/10.1002/2016GL071587.

Jackett, D. R., T. J. McDougall, M. H. England, and A. C. Hirst, 2000: Thermal expansion in ocean and coupled general circulation models. J. Climate, 13, 1384-1405, https://doi.org/ 10.1175/1520-0442(2000)013<1384:TEIOAC >2.0.CO;2.

Jansen, M. F., L. P. Nadeau, and T. M. Merlis, 2018: Transient versus equilibrium response of the ocean's overturning circulation to warming. J. Climate, 31, 5147-5163, https://doi.org/ 10.1175/JCLI-D-17-0797.1.

Katavouta, A., R. G. Williams, and P. Goodwin, 2019: The effect of ocean ventilation on the transient climate response to emissions. J. Climate, 32, 5085-5105, https:// doi.org/10.1175/JCLI-D-18-0829.1.

Kiss, A. E., and Coauthors, 2020: ACCESS-OM2 v1.0: A global ocean-sea ice model at three resolutions. Geosci. Model Dev., 13, 401-442, https://doi.org/10.5194/gmd-13-401-2020.

Klinger, B. A., J. Marshall, and U. Send, 1996: Representation of convective plumes by vertical adjustment. J. Geophys. Res., 101, 18175-18182, https://doi.org/10.1029/96JC00861.

Kuhlbrodt, T., and J. M. Gregory, 2012: Ocean heat uptake and its consequences for the magnitude of sea level rise and climate change. Geophys. Res. Lett., 39, L18608, https://doi.org/10.1029/ 2012GL052952.

,-- , and L. C. Shaffrey, 2015: A process-based analysis of ocean heat uptake in an AOGCM with an eddy-permitting ocean component. Climate Dyn., 45, 3205-3226, https://doi.org/ 10.1007/s00382-015-2534-0.

Large, W. G., J. C. McWilliams, and S. C. Doney, 1994: Oceanic vertical mixing: A review and a model with a nonlocal boundary-layer parameterization. Rev. Geophys., 32, 363-403, https://doi.org/10.1029/94RG01872.

Li, Q., Y. Luo, and F. Liu, 2019: Response of the subtropical gyre circulation in the North Pacific Ocean to $\mathrm{CO}_{2}$ quadrupling. Atmos.Ocean, 57, 307-317, https://doi.org/10.1080/07055900.2019.1666701.

Lowe, J. A., and J. M. Gregory, 2006: Understanding projections of sea level rise in a Hadley Centre coupled climate model. J. Geophys. Res., 111, C11014, https://doi.org/10.1029/2005JC003421.

Luo, Y., J. Lu, F. Liu, and W. Liu, 2015: Understanding the El Niño-like oceanic response in the tropical Pacific to global warming. Climate Dyn., 45, 1945-1964, https://doi.org/10.1007/s00382-014-2448-2.

_ - F. Liu, and J. Lu, 2018: Response of the equatorial Pacific thermocline to climate warming. Ocean Dyn., 68, 1419-1429, https://doi.org/10.1007/s10236-018-1209-x.

Marshall, J., J. R. Scott, K. C. Armour, J. M. C. Maxwell, and K. Anastasia, 2015: The ocean's role in the transient response of climate to abrupt greenhouse gas forcing. Climate Dyn., 44, 22872299, https://doi.org/10.1007/s00382-014-2308-0.

Megann, A., and Coauthors, 2014: GO5.0: The joint NERC-Met Office NEMO global ocean model for use in coupled and forced applications. Geosci. Model Dev., 7, 1069-1092, https:// doi.org/10.5194/gmd-7-1069-2014.

Meijers, A. J., E. Shuckburgh, N. Bruneau, J. B. Sallee, T. J. Bracegirdle, and Z. Wang, 2012: Representation of the Antarctic Circumpolar Current in the CMIP5 climate models and future changes under warming scenarios. J. Geophys. Res., 117, C12008, https://doi.org/10.1029/2012JC008412.

Meinen, C. S., S. L. Garzoli, R. C. Perez, E. Campos, A. R. Piola, M. P. Chidichimo, S. Dong, and O. T. Sato, 2017: Characteristics and causes of deep western boundary current transport variability at $34.5^{\circ}$ S during 2009-2014. Ocean Sci., 13, 175-194, https://doi.org/10.5194/os-13-175-2017.

Meyssignac, B., and Coauthors, 2019: Measuring global ocean heat content to estimate the Earth energy imbalance. Front. Mar. Sci., 6, 432, https://doi.org/10.3389/fmars.2019.00432.

Morrison, A. K., O. Saenko, A. M. Hogg, and P. Spence, 2013: The role of vertical eddy flux in Southern Ocean heat uptake. Geophys. Res. Lett., 40, 5445-5450, https://doi.org/10.1002/2013GL057706.

- S. M. Griffies, M. Winton, W. G. Anderson, and J. L. Sarmiento, 2016: Mechanisms of Southern Ocean heat uptake and transport in a global eddying climate model. J. Climate, 29, 2059-2075, https://doi.org/10.1175/JCLI-D-15-0579.1.

Nagata, Y., Y. Michida, and Y. Umimura, 1988: Variations of positions and structures of the ocean fronts in the Indian Ocean sector of the Southern Ocean. Antarctic Ocean and Resources Variability, D. Sahrhage, Ed., Springer-Verlag, 92-98.

Oppenheimer, M., and Coauthors, 2019: Sea level rise and implications for low lying islands, coasts and communities. IPCC Special Report on the Ocean and Cryosphere in a Changing Climate, H.-O. Pörtner et al., Eds., Cambridge University Press, https://www.ipcc.ch/srocc/chapter/chapter-4-sea-level-rise-andimplications-for-low-lying-islands-coasts-and-communities/.

Palter, J. B., S. M. Griffies, B. L. Samuels, E. D. Galbraith, A. Gnanadesikan, and A. Klocker, 2014: The deep ocean buoyancy budget and its temporal variability. J. Climate, 27, 551-573, https://doi.org/10.1175/JCLI-D-13-00016.1.

Pellichero, V., J. B. Sallée, C. C. Chapman, and S. M. Downes, 2018: The Southern Ocean meridional overturning in the seaice sector is driven by freshwater fluxes. Nat. Commun., 9, 1789, https://doi.org/10.1038/s41467-018-04101-2.

Pontes, G. M., A. Sen Gupta, and A. S. Taschetto, 2016: Projected changes to South Atlantic boundary currents and confluence region in the CMIP5 models: The role of wind and deep ocean changes. Environ. Res. Lett., 11, 094013, https://doi.org/10.1088/1748-9326/11/9/094013.

Qu, T., I. Fukumori, and R. A. Fine, 2019: Spin-up of the Southern Hemisphere super gyre. J. Geophys. Res. Oceans, 124, 154170, https://doi.org/10.1029/2018JC014391.

Redi, M., 1982: Oceanic isopycnal mixing by coordinate rotation. J. Phys. Oceanogr., 12, 1154-1158, https://doi.org/10.1175/ 1520-0485(1982)012<1154:OIMBCR > 2.0.CO;2.

Rhein, M., and Coauthors, 2013: Observations: Ocean. Climate Change 2013: The Physical Science Basis, T. Stocker et al., Eds., Cambridge University Press, 33-115, https://doi.org/ 10.1017/CBO9781107415324.005.

Richter, I., 2015: Climate model biases in the eastern tropical oceans: Causes, impacts and ways forward. Wiley Interdiscip. Rev.: Climate Change, 6, 345-358, https://doi.org/10.1002/WCC.338.

Roemmich, D., J. Church, J. Gilson, D. Monselesan, P. Sutton, and S. Wijffels, 2015: Unabated planetary warming and its ocean structure since 2006. Nat. Climate Change, 5, 240-245, https:// doi.org/10.1038/nclimate2513.

Rykaczewski, R. R., J. P. Dunne, W. J. Sydeman, M. García-Reyes, B. A. Black, and S. J. Bograd, 2015: Poleward displacement of coastal upwelling-favorable winds in the ocean's eastern boundary currents through the 21 st century. Geophys. Res. Lett., $\mathbf{4 2}$, 6424-6431, https://doi.org/10.1002/2015GL064694.

Saenko, O. A., D. Yang, J. M. Gregory, P. Spence, and P. Myers, 2015: Separating the influence of projected changes in air 
temperature and wind on patterns of sea level change and ocean heat content. J. Geophys. Res. Oceans, 120, 5749-5765, https://doi.org/10.1002/2015JC010928.

Sallée, J., E. Shuckburgh, N. Bruneau, A. J. S. Meijers, T. J. Bracegirdle, Z. Wang, and T. Roy, 2013: Assessment of Southern Ocean water mass circulation and characteristics in CMIP5 models: Historical bias and forcing response. J. Geophys. Res. Oceans, 118, 1830-1844, https://doi.org/ 10.1002/jgrc.20135.

Santos, F., M. Gomez-Gesteira, M. DeCastro, and I. Alvarez, 2012: Differences in coastal and oceanic SST trends due to the strengthening of coastal upwelling along the Benguela Current system. Cont. Shelf Res., 34, 79-86, https://doi.org/ 10.1016/j.csr.2011.12.004.

Schmidtko, S., G. C. Johnson, and J. M. Lyman, 2013: MIMOC: A global monthly isopycnal upper-ocean climatology with mixed layers. J. Geophys. Res. Oceans, 118, 1658-1672, https:// doi.org/10.1002/jgrc.20122.

Seidov, D., 2009: Heat transport, oceanic and atmospheric. Encyclopedia of Paleoclimatology and Ancient Environments, V. Gornitz, Ed., Springer, 407-409, https://doi.org/10.1007/978-1-4020-4411-3_102.

Sen Gupta, A., L. C. Muir, J. N. Brown, S. J. Phipps, P. J. Durack, D. Monselesan, and S. E. Wijffels, 2013: Climate drift in the CMIP3 models. J. Climate, 25, 4621-4640, https://doi.org/ 10.1175/JCLI-D-11-00312.1.

Shao, A. E., S. T. Gille, S. Mecking, and L. Thompson, 2015: Properties of the subantarctic front and polar front from the skewness of sea level anomaly. J. Geophys. Res. Oceans, 120, 5179-5193, https://doi.org/10.1002/2015JC010723.

Snow, K., A. M. C. Hogg, S. M. Downes, B. M. Sloyan, M. L. Bates, and S. M. Griffies, 2015: Sensitivity of abyssal water masses to overflow parameterisations. Ocean Modell., 89, 84-103, https:// doi.org/10.1016/j.ocemod.2015.03.004.

Stewart, K. D., W. Kim, S. Urakawa, A. M. Hogg, S. Yeager, H. Tsujino, H. Nakano, and A. E. Kiss, 2020: JRA55-dobased repeat year forcing datasets for driving ocean-sea-ice models. Ocean Modell., 147, 101557, https://doi.org/10.1016/ j.ocemod.2019.101557.

Stocker, T. F., 2013: The ocean as a component of the climate system. Ocean Circulation and Climate: A 21st Century Perspective, G. Siedler et al., Eds., 2nd ed. Academic Press, 330, https://doi.org/10.1016/B978-0-12-391851-2.00001-5.

Strub, P. T., V. Combes, F. A. Shillington, and O. Pizarro, 2013: Currents and processes along the eastern boundaries. Ocean Circulation and Climate: A 21st Century Perspective, G. Siedler et al., Eds., Academic Press, 339-384.

Sydeman, W. J., M. García-Reyes, D. S. Schoeman, R. R. Rykaczewski, S. A. Thompson, B. A. Black, and S. J. Bograd, 2014: Climate change and wind intensification in coastal upwelling ecosystems. Science, 345, 77-80, https://doi.org/ 10.1126/science.1251635.

Tamsitt, V., L. D. Talley, M. R. Mazloff, and I. Cerovečki, 2016: Zonal variations in the Southern Ocean heat budget. J. Climate, 29, 6563-6579, https://doi.org/10.1175/JCLI-D15-0630.1.

Todd, A., and Coauthors, 2020: Ocean-only FAFMIP: Understanding regional patterns of ocean heat content and dynamic sea level change. J. Adv. Model. Earth Syst., https://doi.org/ 10.1002/essoar.10501557.1, in press.

Trenberth, K. E., and J. M. Caron, 2001: Estimates of meridional atmosphere and ocean heat transports. J. Climate, 14,
3433-3443, https://doi.org/10.1175/1520-0442(2001)014<3433: EOMAAO $>2.0 . \mathrm{CO} ; 2$.

Tsujino, H., and Coauthors, 2018: JRA-55 based surface dataset for driving ocean-sea-ice models (JRA55-do). Ocean Modell., 130, 79-139, https://doi.org/10.1016/j.ocemod.2018.07.002.

Vecchi, G. A., and A. T. Wittenberg, 2010: El Niño and our future climate: Where do we stand? Wiley Interdiscip. Rev.: Climate Change, 1, 260-270, https://doi.org/10.1002/wcc.33.

Wang, D., T. C. Gouhier, B. A. Menge, and A. R. Ganguly, 2015: Intensification and spatial homogenization of coastal upwelling under climate change. Nature, 518, 390-394, https:// doi.org/10.1038/nature14235.

Wang, G., S. P. Xie, R. X. Huang, and C. Chen, 2015: Robust warming pattern of global subtropical oceans and its mechanism. J. Climate, 28, 8574-8584, https://doi.org/10.1175/JCLID-14-00809.1.

Wenegrat, J. O., L. N. Thomas, J. Gula, and J. C. McWilliams, 2018: Effects of the submesoscale on the potential vorticity budget of ocean mode waters. J. Phys. Oceanogr., 48, 2141-2165, https://doi.org/10.1175/JPO-D-17-0219.1.

Wijffels, S. E., D. Roemmich, D. Monselesan, J. A. Church, and J. Gilson, 2016: Ocean temperatures chronicle the ongoing warming of Earth. Nat. Climate Change, 6, 116-118, https:// doi.org/10.1038/nclimate2924.

Winton, M., S. M. Griffies, B. L. Samuels, J. L. Sarmiento, and T. L. Licher, 2013: Connecting changing ocean circulation with changing climate. J. Climate, 26, 2268-2278, https://doi.org/ 10.1175/JCLI-D-12-00296.1.

Wolfe, C. L., P. Cessi, J. L. McClean, and M. E. Maltrud, 2008: Vertical heat transport in eddying ocean models. Geophys. Res. Lett., 35, L23605, https://doi.org/10.1029/2008GL036138.

Wu, L., and Coauthors, 2012: Enhanced warming over the global subtropical western boundary currents. Nat. Climate Change, 2, 161-166, https://doi.org/10.1038/nclimate1353.

Xie, P., and G. K. Vallis, 2012: The passive and active nature of ocean heat uptake in idealized climate change experiments. Climate Dyn., 38, 667-684, https://doi.org/10.1007/s00382-0111063-8.

Xie, S.-P., C. Deser, G. A. Vecchi, J. Ma, H. Teng, and A. T. Wittenberg, 2010: Global warming pattern formation: Sea surface temperature and rainfall. J. Climate, 23, 966-986, https://doi.org/10.1175/2009JCLI3329.1.

Yamaguchi, R., and T. Suga, 2019: Trend and variability in global upper-ocean stratification since the 1960s. J. Geophys. Res. Oceans, 124, 8933-8948, https://doi.org/10.1029/2019JC015439.

Yang, H., G. Lohmann, W. Wei, M. Dima, M. Ionita, and J. Liu, 2016: Intensification and poleward shift of subtropical western boundary currents in a warming climate. J. Geophys. Res. Oceans, 121, 4928-4945, https://doi.org/10.1002/2015JC011513.

, and Coauthors, 2020: Poleward shift of the major ocean gyres detected in a warming climate. Geophys. Res. Lett., 47, e2019GL085868, https://doi.org/10.1029/2019GL085868.

Zanna, L., S. Khatiwala, J. M. Gregory, J. Ison, and P. Heimbach, 2019: Global reconstruction of historical ocean heat storage and transport. Proc. Natl. Acad. Sci. USA, 116, 1126-1131, https://doi.org/10.1073/pnas.1808838115.

Zika, J. D., N. Skliris, A. Blaker, R. Marsh, A. J. G. Nurser, and S. Josey, 2018: Improved estimates of water cycle change from ocean salinity: The key role of ocean warming. Environ. Res. Lett., 13, 074036, https://doi.org/10.1088/1748-9326/aace42. 